\title{
A parametric study of crack propagation in paintings caused by temperature and relative humidity cycles based on irreversible cohesive zone model
}

Mohammad Yaghoub Abdollahzadeh Jamalabadi ( $\sim$ abdollahzadeh@ikifp.edu.pl )

Research article

Keywords: Life prediction, fracture mechanics, irreversible cohesive zone model, low-cycle fatigue, Prony series, historical paintings

Posted Date: June 30th, 2020

DOI: https://doi.org/10.21203/rs.3.rs-38068/v1

License: (9) This work is licensed under a Creative Commons Attribution 4.0 International License.

Read Full License 


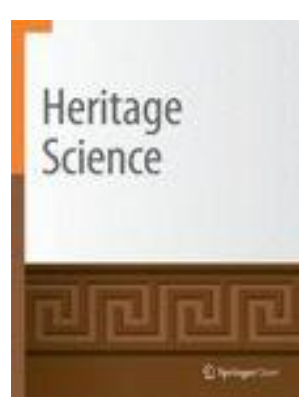

$1 \quad$ Article

2 A parametric study of crack propagation in paintings

3 caused by temperature and relative humidity cycles based

4 on irreversible cohesive zone model

Mohammad Yaghoub Abdollahzadeh Jamalabadi

Jerzy Haber Institute of Catalysis and Surface Chemistry, Polish Academy of Sciences, 30-239, Krakow, Poland and

Email : abdollahzadeh@ikifp.edu.pl

Abstract: The current paper aims to use an irreversible cohesive zone model to investigate the effects of temperature and relative humidity cycles on multilayer thin-film paintings crack pattern. The homogenous one-dimensional paint layers composed of alkyd and acrylic gesso over a canvas foundation (support) with known constant thicknesses are considered as the mechanical model of painting. Experimental data used for mathematical modeling of canvas as a linear elastic material and paint as a viscoelastic material with the Prony series. Fatigue damage parameters such as crack initiation time and maximum loads are calculated by an irreversible cohesive zone model used to control the interface separation. With the increase of the painting thickness and/or the initial crack length, the value of the maximum force increases. Moreover, by increasing the relative humidity $(\mathrm{RH})$ and the temperature difference at loading by one cycle per day, the values of initiation time of delamination decrease. It is shown that the thickness of painting layers is the most important parameter in crack initiation times and crack growth rate in historical paintings in museums and conservation settings.

Keywords: Life prediction; fracture mechanics; irreversible cohesive zone model; low-cycle fatigue; Prony series; historical paintings

\section{Introduction}

A painting structure consists of support (wood panel and canvas), glue sizing, ground, and paint film (binding media and pigments). Different mechanical properties of the various layers (support, ground, and paint) through aging can lead to craquelure in paintings. Environmental changes such as humidity caused stress in the different paint layers which sometimes leads to strains larger than $1 \%$ (restrained layers) and produces a stress-rise in the painting or shrinkage of the glue size during dryness. Accumulation of such failures in cyclic load results in fatigue, plastic deformation (ductile failure), and brittle failure.

The interface between various materials, for example, the interface between a solid gravity dam and the bedrock, is constantly a powerless connection, advancing split initiation and prompting break even under administration loads [1]. The irreversible cohesive zone model is an appropriate system to investigate and assess the potential crack at a bi-material interface [2]. In light of the irreversible cohesive zone model, some interfacial crack parameters, let's say, crack and break durability were explored through exploratory and numerical studies [3-4]. The exploratory examinations showed that the greatness of interfacial unpleasantness would affect the previously mentioned interfacial crack parameters, driving analysts to contemplate its impact by researching examples with smooth interfaces and false notching interfaces [5]. The problem of stress analysis of a plate having an elliptical hole $\left(\sigma_{y y}(c, 0)=\sigma_{L}(1+2 c / b)\right)$ is the first case in this field. For the 
first time, Griffith (based on thermodynamics, $U=U_{\text {strain,bending }}+U_{\text {strain,tensile }}+U_{\text {surface }}-W_{\text {load }}$ ) proposed the energy-balance concept of fracture $(d U / d c=0)$. Figure 1 presents the schematic of the 2D plane stress problem of a plate having an elliptical hole.

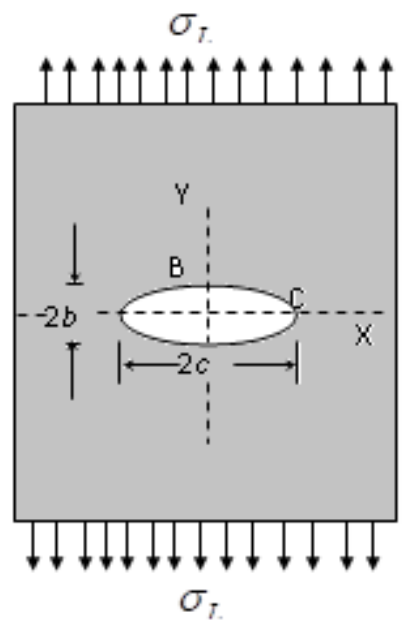

Figure 1. Schematic of 2D plane stress problem of a plate having the elliptical hole.

Historical paintings in museums are one of the materials that suffer various low-stress cycles which can cause the initiation of a crack or accelerate the crack growth rate [6]. For semi-weak materials, the fracture propagation zone lies before the split-tip and pulls in huge concerns when considering the nonlinear reaction of a designing structure built with semi- brittle materials during the crack propagation [7]. The impact of the fracture propagation zone on the crack parameters of cement, as a sort of semi-brittle material, has been widely examined over the most recent couple of decades [8-10]. The size impact of the crack was observed to be connected with the fracture propagation zone properties [11, 12], showing that the fracture propagation zone length specifically diminishes quickly when the split causes near the top surface of an example [13]. Thusly, the locality crack was observed to be not consistent during the entire crack propagation and rather diminished with the decrease of the fracture propagation zone length [14]. Consolidating the hypothetical and exploratory investigations, a bilinear model on neighborhood crack vitality conveyance was proposed to ascertain the genuine explicit break energy [15].

Numerous non-linear models have been established to characterize the fatigue parameters such as size, shape, material, and, test method. J-integral is used by many methods. The cohesive crack model used fracture energy, strength in uni-axial, and elasticity modulus [16]. As well, the crack band model also uses a width of micro-cracks [17]. More fracture-based methods have used the benefit of critical stress intensity factor and critical crack tip opening displacement such as a two-parameter fracture model [18], while the size-effect model for infinitely large test specimens uses critical effective crack length extension (at peak load). Other parameters such as the critical effective extension of crack and critical stress intensity factor (effective crack model), unstable fracture toughness and initial cracking toughness (double-k fracture model ) [19], unstable fracture energy released and initiation fracture energy release (double-g fracture model) [20] are the base of other methods. The cohesive zone method is a classic and simpler method than the above-mentioned methods [16-20]. In comparison to linear elastic fracture mechanics or crack tip open displacement methods, it can forecast the un-cracked configurations manners (such as those have blunt notches), larger non-linear zone, and start without initial crack.

The huge impact of a changing fracture propagation zone on solid break attributes and the whole crack propagation has drawn in logical and building networks. The significant examinations have been brought out through test investigations [21-23] and numerical simulations [22,23]. Furthermore, as one three-dimensional impact on break investigation, a coupled break mode was found to exist in the split thick plate under shear or out-plane stacking, and the power of the coupled model was essentially affected by the thickness of the plate in the three-dimensional limited component analysis [24-26]. Be that as it may, the examination on the development of the fracture propagation zone during the total crack propagation at a stone solid interface has been minimally detailed. As to shake concrete interfacial crack, it is beneficial to bring up that the determined 
break energy dependent on crack length without considering the fracture propagation zone is not as much as that dependent on nonlinear crack mechanics [28] by $83 \%$. Along these lines, it is huge to join the investigation of the fracture propagation zone development at the stone solid interface when investigating the crack system and evaluating the nonlinear reaction of a solid structure developed on bedrock [29]. In the interim, the split engendering criteria in numerical strategies have been generally examined, which show the component of break development in semi-brittle materials like cement. Determination of the fracture energy of mortar and concrete using three-point bend tests on notched beams is performed by numerous specialists [30-31]. Considering the complex stress distribution at the notch tip under mixed-mode loading, a strain energy density and crack zone model fracture criterion was used to predict the critical load for blunt U- and V-notched brittle specimens [32].

Artists' paintings are composed of polymeric layers. One of the main problems in the polymeric coating materials is to endure mechanical fractures over a continued loading. Painting on canvas made the use of binder for the pigmented paint layers [33]. The pigment material provides the color, the binding medium a substance that guarantees that the colored material remains in the applied place. Common paint binders are Steam-pressed linseed oil, Acrylic Resins, and Alkyd resins. The impacts of temperature and changes in the vapor content of air on the mechanical properties of the painting layers in artwork have been examined in many works [34]. In painting, which is made of various layers, delamination growth is likely to occur under mixed-mode loading. Delamination between an alkyd configuration layer and acrylic prepared canvas because of cyclic changes in RH has recently been explored [35]. Common environmental control specifications for galleries and museums are relative humidity at 50 or $55 \pm 5 \%$ relative humidity $(\mathrm{RH})$ and temperature in winter at $19 \pm 1{ }^{\circ} \mathrm{C}$ and summer at $24 \pm 1{ }^{\circ} \mathrm{C}$ [36]. The work executes the irreversible firm zone model in a limited component examination to display the interface between alkyd paint and prepared the canvas, which results in an alteration to the footing detachment law to represent fatigue failure. Mecklenburg [37] demonstrated that the constituents show diverse dimensional and stress-strain reactions relying upon the ecological conditions. A straightforward order of splits in other works of literature was first efficiently connected by Keck [38]. Recently, the type of separation in the interfacial interaction of modern paint layers has been distinguished by Young [39]. Craquelure and interfacial splits have likewise been distinguished, and poor bond characteristics featured when blended-media paints are utilized on canvas for example in a blend of acrylic and alkyd paint layers. Inverse analysis can be employed to optimize the coating design [40-41].

Creep [42] and fracture [43] are classic topics that initially manipulated by linear theories. The nonlinear models of pre-existent crack propagation are developed for the first time by Dugdale [44] and later by Barenblatt [45].

In the present study, a two-layer painting is simulated in $3 \mathrm{D}$ stress conditions with the finite element method. This simulation has been carried out in steady-state, isothermal, and single-phase and the effect of temperature variations, layer thickness, and initial crack length on the crack propagation time and the maximum load of the painting are investigated. As well, the distribution of the stress in the painting regions have been studied and evaluated.

\section{Model details and validation}

In this study, a single support canvas with a paint membrane is modeled in two dimensions and isothermal. The schematic of the computational region, including the paint membrane, the canvas layer, and the interface, is illustrated in Fig. 2a. Forces are applied to the top edges at the cracked end and the center of the test specimen. In this figure, the upper part of the geometry is the painting and the lower part is the canvas. In this figure, the crack of composite structures develops as delamination between plies. As the geometry of the problem is shown in Figure 2a, the layers cracked along a ply interface, and the test specimen is supported at the outermost bottom edges. Because of the symmetry, just half of the test specimen is considered and a symmetry boundary condition is applied. The experimental setup of loading is plotted in Figure $2 \mathrm{~b}$. Table 1 shows the geometry parameters of the experimental setup in [27]. 

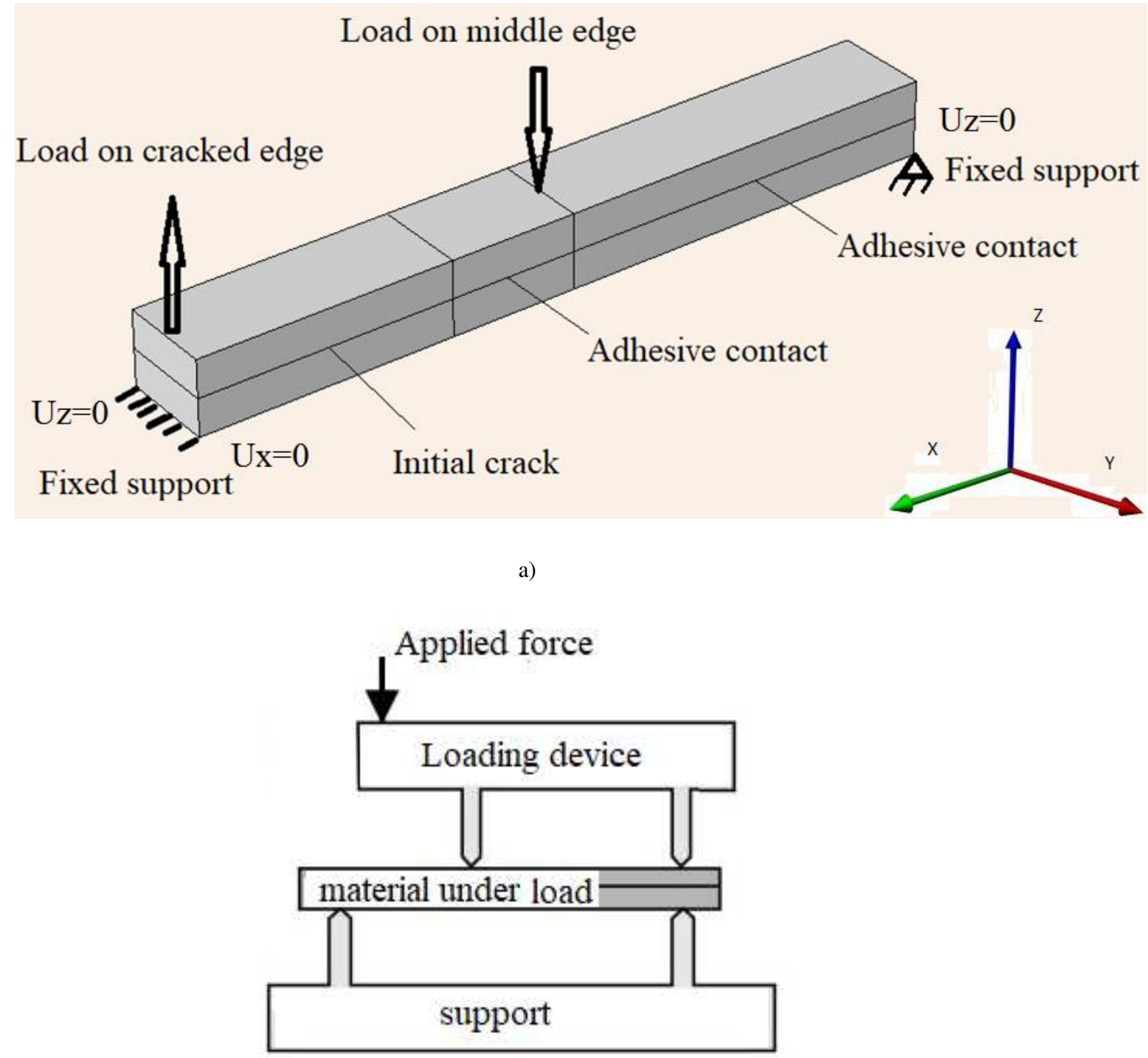

Figure 2. a) schematic of the computational domain and boundary conditions. b) Schematic of the experimental setup used for validation.

Table 1. Geometry and main physical parameters [27].

\begin{tabular}{cccc}
\hline symbol & value & unit & description \\
\hline$l_{\mathrm{b}}$ & 102 & $\mathrm{~mm}$ & Length \\
$\mathrm{w}_{\mathrm{b}}$ & 25.4 & $\mathrm{~mm}$ & Width \\
$\mathrm{h}_{\mathrm{b}}$ & 3.12 & $\mathrm{~mm}$ & Thickness \\
$\mathrm{c}_{\mathrm{l}}$ & 34.1 & $\mathrm{~mm}$ & Initial crack length \\
$\mathrm{K}_{\mathrm{p}}$ & $10^{6}$ & $\mathrm{~N} / \mathrm{mm}^{3}$ & Penalty Stiffness \\
$\mathrm{N}_{\text {strength }}$ & 80 & $\mathrm{MPa}$ & Normal Tensile Strength \\
$\mathrm{S}_{\text {strength }}$ & 100 & $\mathrm{MPa}$ & Shear Strength \\
$\mathrm{G}_{\mathrm{Ic}}$ & 0.969 & $\mathrm{~kJ} / \mathrm{m}^{2}$ & Mode I critical energy release \\
$\mathrm{G}_{\mathrm{IIc}}$ & 1.719 & $\mathrm{~kJ} / \mathrm{m}^{2}$ & Mode II critical energy release \\
$\eta$ & 2.284 & - & $\mathrm{mm}$ \\
$\delta$ & 0 & - & Exponent of Benzeggagh and Kenane (B-K) criterion \\
$\mu$ & 0.5 & $\mathrm{GPa}$ & Initial Displacement parameter \\
$\mathrm{E}_{\mathrm{X}}$ & 122.7 & $\mathrm{GPa}$ & Mode mixity ratio \\
$\mathrm{E}_{\mathrm{Y}}, \mathrm{E}_{\mathrm{Z}}$ & 10.1 & - & Young's modulus, along fibers \\
$v_{\mathrm{YZ}}$ & 0.45 & - & Young's modulus, across fibers \\
$v_{\mathrm{XY}}=v_{\mathrm{XZ}}$ & 0.25 & Poisson's ratio, along fibers \\
$\mathrm{G}_{\mathrm{YZ}}$ & 3.7 & $\mathrm{GPa}$ & Poisson's ratio, across fibers \\
$\mathrm{G}_{\mathrm{XY}}, \mathrm{G}_{\mathrm{XZ}}$ & 5.5 & $\mathrm{GPa}$ & Shear modulus, along fibers \\
\hline & & & Shear modulus, across fibers \\
\hline
\end{tabular}


The main parameters in FEA modeling of the current system are stress $\left(\sigma=\frac{P L}{L_{0} A_{0}}\right)$ and strain ( $\varepsilon=\ln \frac{L}{L_{0}}$ ). The properties of unidirectional laminates composite AS4/PEEK (APC2) which is a carbon fiber reinforced composite used for experimental setup [27]. Correspondingly, the geometric, material properties of the laminate composite, and physical properties of the fracture modeling and validation are summarized in Table 1. This specification is derived from the experimental study by Camanho et al. [27]. The orthotropic linear elastic properties assume that the longitudinal direction is alongside the global longitudinal direction. The experimental tests are performed by applying different loads in the middle and at the end of the test specimen. The experimental results relate the load to the displacement of the point of application of the load in the lever (load-point displacement). The lever is not simulated here. In numerical modeling, the cohesive zone elements divided into two groups point and continuous cohesive zone elements. Here to calculate delamination onset and growth surface elements used for cohesive zone elements. The initial crack length is $c_{1}$. Traction (obey bilinear traction-separation law) linearly increases (with a stiffness $K p$ ) in anticipation of the ultimate displacement jump $\left(u_{0}\right)$ where opening crack reaches a failure initiation. After that the stiffness reductions by an increase of the damage (material softens irreversibly) till the failure at zero stiffness $\left(u_{f}\right)$. In mode I separation displacement is normal to an interface while on mode II and III separation displacement is tangential.

The crack stress modes are:

- Mode I (opening mode): the displacements of the crack surfaces are perpendicular to the plane of the crack.

- Mode II (sliding mode): the displacements of the crack surfaces are in the plane of the crack and perpendicular to the leading edge of the crack.

- Mode III (tearing mode): the crack surface displacements are in the plane of the crack and parallel to the leading edge of the crack.

For the current study the mixed-mode mode I, mode II, and mode III separation displacement are included then a combination of separation displacement is used as modeled by Kenane and Benzeggagh [38]. Note that for mode I, damage only accumulates positive normal separation, while in shear loading, damage occurs for both shear displacement directions.

Table 2. The relative difference with benchmark solution for nine different numbers of meshes.

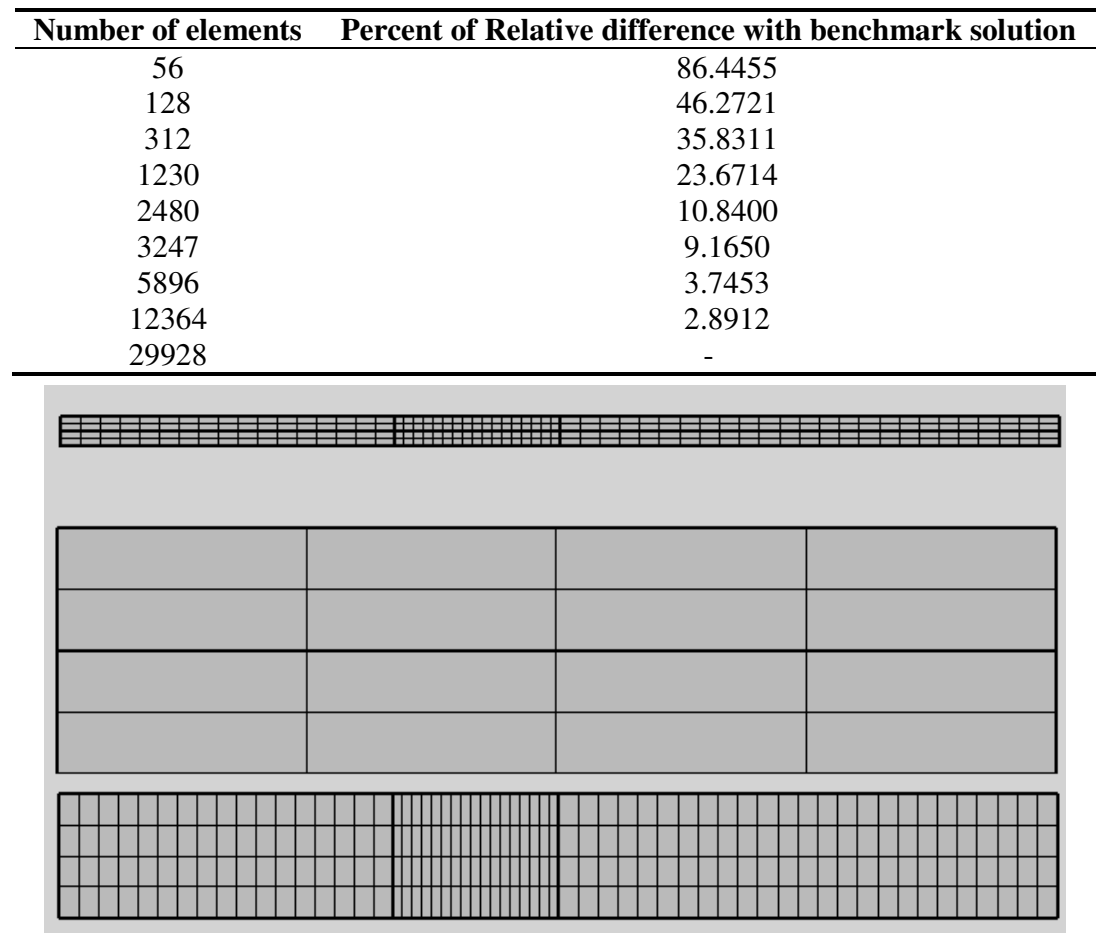





Figure 3. Multi-grid mesh for two layers (a) top view, right view, and front view (b) isometric view (c) irregular meshes.

To test the independence of results from the mesh, nine different meshes of a structured type have been produced and the results are compared with each other. Here meshes with several refinement degrees are used. Table 2 shows the results of different meshes. From really coarse mesh (only 56 elements) to finer mesh (29928 elements). It is well known that the process zone size is a fraction of this characteristic length, therefore one should not provide calculations for mesh sizes that are larger than $1 / 10$ or $1 / 20$ of this characteristic length. Although it is nonsense to use such coarse meshes (only 56 elements) regarding the cohesive zone characteristic length, its results could be used as an initial guess for finer cases. Considering the characteristic length of the cohesive zone model, the largest mesh size with 29928 elements is less than 1/200 of characteristic length of the cohesive zone model and all the presented calculations are meaningful accordingly. Percent of relative difference with benchmark solution is the average of percent of the solution with the solution of the 29928 elements case. To check the precision of different meshes, a bi-linear irreversible traction-separation curve is obtained for each mesh; the relative error shown in table 2 presents the average difference of traction-separation achieved from numerical simulation of a sample mesh and traction-separation from an experimental study by Camanho et al. [27]. As shown in Table 2, the results are close to each other for the 12364 and 29928 meshes, and finally the mesh number has been selected 29928. Figure 3 reveals multi-grid mesh for two layers from the 181 top view, right view, front view, an isometric view. The finer grid is used in the crack growth region. To 
increase the accuracy of simulation, given that the damage occurs in the midline of the domain, the mesh of this section is finer, and a multi-grid method is used for meshing (see Fig. 3). Results using irregular meshes are same as regular meshes and irregular meshes are presented in Figure 3 (c).

For validation, a numerical study has been used from the experimental work of Camanho et al, which is shown in Fig. 4. As can be seen, there is an acceptable agreement between the empirical work of [27] and numerical simulation presented here. Although figure 5 does not provide a comparison of data concerning crack propagation, it compares the linear elastic part of the curve for which no crack propagation occurs. As well the start stage of crack propagation is calculated perfectly. As shown material resistance to crack extension firstly is a linear and continuous balance between consumed energy and released energy is maintained during slow stable crack growth. Because of slow stable crack extension, finally, the rising shape is observed (it is flat for truly brittle material).

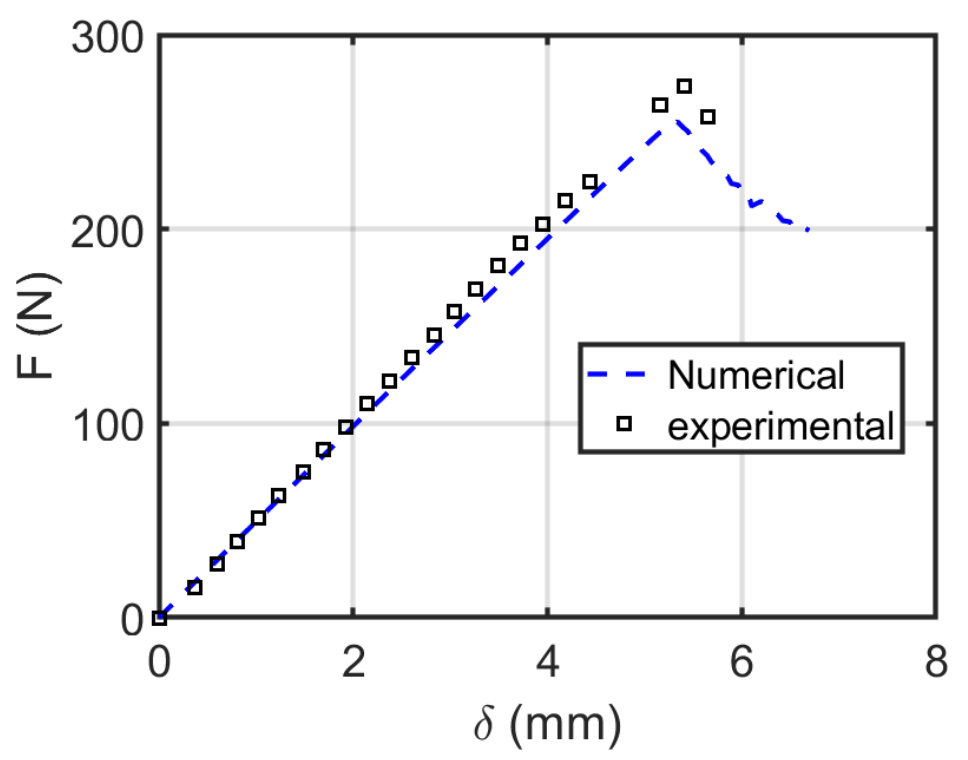

Figure 4. Comparison between the numerical simulation results and the experimental study by Camanho et al [27].

\section{Governing equations}

The stress-strain formula for homogeneous materials is as follows.

$$
\begin{aligned}
& \left\{\begin{array}{l}
\varepsilon_{x} \\
\varepsilon_{y} \\
\varepsilon_{z}
\end{array}\right\}=\frac{1}{E}\left[\begin{array}{ccc}
1 & -v & -v \\
-v & 1 & -v \\
-v & -v & 1
\end{array}\right]\left\{\begin{array}{l}
\sigma_{x} \\
\left.\sigma_{y}\right\}+\left\{\begin{array}{c}
0 \\
\sigma_{z}
\end{array}\right\} \\
\varepsilon_{f}
\end{array}\right\} \\
& \left\{\begin{array}{l}
\varepsilon_{x} \\
\varepsilon_{y} \\
\varepsilon_{z}
\end{array}\right\}=\frac{1}{E}\left[\begin{array}{ccc}
1 & -v & -v \\
-v & 1 & -v \\
-v & -v & E / E_{t}
\end{array}\right]\left\{\begin{array}{l}
\sigma_{x} \\
\sigma_{y} \\
\sigma_{z}
\end{array}\right\}+\left\{\begin{array}{l}
0 \\
0 \\
\varepsilon_{0}
\end{array}\right\}
\end{aligned}
$$

where $\varepsilon_{x}, \varepsilon_{y}$ and $\varepsilon_{z}$ are the principal strains, $\sigma_{x}, \sigma_{y}$ and $\sigma_{z}$ are the principal stresses, $\varepsilon_{f}$ ( $\varepsilon_{f}=\frac{\delta_{f}}{h_{c}}$ ) is the fracture strain by the opening of the micro cracks, E is Young's elastic modulus, $v$ is its Poisson's ratio, $h_{c}$ is the width of the fracture front, $\delta_{f}$ is the crack displacement, $\varepsilon_{0}$ is the strain at the end of strain-softening at which the micro-cracks coalesce into a continuous crack and $\sigma_{z}$ vanishes. The 2nd Piola-Kirchhoff stress tensor for the material with the Poisson ratio of $v_{\mathrm{s}}$ and Young's modulus of $\mathrm{E}$ is defined by 
$\mathbf{S}=\frac{E}{1+v_{s}} \mathbf{E}+\frac{v_{s} E}{\left(1+v_{s}\right)\left(1-2 v_{s}\right)}(\operatorname{tr} \mathbf{E}) \mathbf{I}$

while 2nd Piola-Kirchhoff stress tensor is related to the Cauchy stress tensor through the geometric transformation of

$\mathbf{S}=J \mathbf{F}^{-1} \boldsymbol{\sigma}_{s} \mathbf{F}^{-\mathrm{T}}$

The dynamics of the displacement of the solid structure is

$\rho \frac{\partial^{2} \mathbf{u}_{s}}{\partial t^{2}}=\nabla \cdot\left(\mathbf{J} \boldsymbol{\sigma}_{s} \mathbf{F}^{-T}\right)=\nabla \cdot\left(\mathbf{F}^{-\mathrm{T}} \mathbf{F}\left(\lambda(\operatorname{tr}(\mathbf{E}) \mathbf{I}+2 \mu \mathbf{E}) \mathrm{F}^{\mathrm{T}}\right)\right.$

where a Rayleigh damping factor proportional to the stiffness is used for the beam and $\mathbf{J}$ is the determinant of $\mathbf{F}$ and the deformation gradient tensor is computed from

$\mathbf{F}=\mathbf{I}+\nabla \mathbf{u}_{s}$

and for the St. Venant-Kirchhoff material the Lagrange strain tensor $\mathbf{E}$ is calculated by

$\mathbf{E}=\frac{1}{2}\left(\mathbf{F}^{\mathrm{T}} \mathbf{F}-\mathbf{I}\right)$

The initial condition of the system is the stationary condition. The presented dynamic formulation in Eq. (5) would be applied to quasi-static simulations. The quasi-static solution is updated in each iteration of the dynamic solution. In a quasi-static scheme, the transient term is collect the residuals and let the unbalanced of the system to relax in longer times.

Ogden and van der Waals models are usually used in literature for uniaxial tension. Hagan et al. [29] announced that the mechanical reaction of latex paints under uniaxial stacking can be depicted utilizing the hyperelastic, van der Waals model, related to the time needy, viscoelastic Prony arrangement. They used pigments and coloring material of titanium white acrylic gesso and phthalo blue alkyd. Using the viscoelastic model, one can model the creep at constant stress [37], relaxation at a constant displacement, recovery without the stress, constant rate stress, and constant rate strain.

The boundary conditions are the supports fixed in two horizontal directions and the test are monotonic not cyclic. The time-dependent manner of the viscoelastic material is given by the Prony series as (see Table 3 for the constant of Prony Series):

$\sigma(t)=\sigma_{0} g_{e}+\int_{0}^{t} \sum_{M}^{i=1} g_{i} e^{-(t-s) / \tau_{i}} \frac{d \sigma_{0}}{d s} d s$

where $\left(g_{e}+\sum_{M}^{i=1} g_{i}=1\right)$ and the stress as a function of $\lambda\left(\lambda=\frac{L}{L_{0}}, \sigma_{0}=\lambda f=\lambda \frac{d W}{d \lambda}\right)$ corresponding

to uniaxial loading can be derived as follows:

$\sigma_{0}=\lambda \mu\left(1-\lambda^{-3}\right)\left[1-\left(\frac{\lambda^{2}+2 \lambda^{-1}-3}{\lambda_{m}^{2}-3}\right)^{-0.5}-\alpha\left(\frac{\lambda^{2}+2 \lambda^{-1}-3}{2}\right)^{0.5}\right]$

The strain vitality capability of the van der Waals model [31] is given by:

$W=\mu\left\{-\left(\lambda_{m}^{2}-3\right)\left[\ln \left(1-\sqrt{\frac{I-3}{\lambda_{m}^{2}-3}}\right)+\sqrt{\frac{I-3}{\lambda_{m}^{2}-3}}\right]-\frac{2}{3} \alpha\left(\frac{I-3}{2}\right)^{\frac{3}{2}}\right\}$

where $\alpha$ is the chain interaction parameter (0.5), $\lambda_{m}$ is the locking stretch (for Alkyd is 8 and for Gesso is 10), $\mu$ is the initial shear modulus (for Alkydis $75 \mathrm{MPa}$ and for Gesso is $125 \mathrm{MPa}$ ) and $I$ is the first stretch invariant which under uniaxial tension is given by: 
$I=\lambda^{2}+\lambda^{-1}$

Table 3. Constant of Prony Series.

\begin{tabular}{ccc}
\hline $\boldsymbol{\tau}_{\boldsymbol{i}}(\mathbf{s})$ & $\boldsymbol{g}_{\boldsymbol{i}}($ Alkyd $)$ & $\boldsymbol{g}_{i}$ (Gesso) \\
\hline $1.00 \mathrm{E}-01$ & 0.730 & 0.727 \\
$1.00 \mathrm{E}+00$ & 0.145 & 0.150 \\
$1.00 \mathrm{E}+01$ & 0.050 & 0.050 \\
$1.00 \mathrm{E}+02$ & 0.032 & 0.030 \\
$1.00 \mathrm{E}+03$ & 0.020 & 0.022 \\
$1.00 \mathrm{E}+04$ & 0.013 & 0.020 \\
$g_{e}$ & 0.01 & 0.001 \\
\hline
\end{tabular}

Table 4. Material properties of the cohesive zone model interface.

\begin{tabular}{cccc}
\hline symbol & value & unit & description \\
\hline $\mathrm{S}_{\mathrm{T}}$ & $8 \times 10^{7}$ & $\mathrm{~Pa}$ & Normal tensile strength \\
$\mathrm{S}_{\mathrm{s}}$ & $10^{8}$ & $\mathrm{~Pa}$ & Shear strength \\
$\mathrm{P}_{\mathrm{n}}$ & $10^{12}$ & $\mathrm{~Pa}$ & Penalty stiffness \\
$\mathrm{G}_{\mathrm{ct}}$ & 970 & $\mathrm{~J} / \mathrm{m}^{2}$ & Critical energy release rate, tension \\
$\mathrm{G}_{\mathrm{cs}}$ & 1720 & $\mathrm{~J} / \mathrm{m}^{2}$ & Critical energy release rate, shear \\
$\mu$ & 2.3 & - & The exponent of the Benzeggagh and Kenane (B-K) criterion \\
\hline
\end{tabular}

Table 4 shows the material properties of the cohesive zone model interface. Parameters are defined in Table 4, which are not the same as those presented in Table 1 as Table 1 data is for benchmark Table 4 data is for painting. Both parameters are finally used in the CZM. Based on the analytical method vertical separation of the cantilever tip and the energy release rates for modes I and II are

$\Delta=\frac{P\left[7(a+0.42 \chi h)^{3}+(L+2 \chi h)^{3}\right]}{2 E B h^{3}}$

$G_{I}=\frac{3 P^{2}(a+\chi h)^{2}}{E B^{2} h^{3}}$

$G_{I I}=\frac{9 P^{2}(a+0.42 \chi h)^{2}}{4 E B^{2} h^{3}}$

235 where $\mathrm{P}$ denotes the loading force; E is Young's modulus; a is the crack length; B is the width of the beam;

$236 \mathrm{~h}$ is the thickness of beam; $\mathrm{I}$ is the second moment of area of the cantilever beam $\left(I=B h^{3} / 12\right)$; $\chi$ is the

237 correction parameter $\left(\chi=\sqrt{\frac{E}{11 G}\left(3-2\left(\frac{1.18 E / G}{1.18 E / G+1}\right)^{2}\right)}\right) ; \mathrm{G}$ is the shear modulus. Cyclic loading can

238 be described using the stress amplitude, mean stress, and stress range, respectively. Based on Paris law the

239 fatigue crack growth rate is defined

$\frac{d}{d N} a=C\left(K_{\max }-K_{\min }\right)^{m}$

240 The cohesive zone model assumes a linear relationship between cohesive stress response

$\sigma=(1-D)\left(1-D_{c}\right) K_{0} \delta$ 
and damage parameter is defined

$D=\frac{\delta_{\text {final }}\left(\delta-\delta_{\text {initial }}\right)}{\delta\left(\delta_{\text {final }}-\delta_{\text {initial }}\right)}$, for $\delta>\delta_{\text {initial }}$

$D=0$ for $\delta \leqslant \delta_{\text {initial }}$

which the stiffness is changed with cyclic loading to $\left(1-\mathrm{D}_{\mathrm{c}}\right)$ times. The onset of delamination growth is defined as:

$N \geq\left(G_{\max }-G_{\min }\right)^{-0.1}$

where the energy release rate at maximum loading is larger than the $G_{\text {threshold }}$ or one percent of critical energy release rate which is 0.8 . As well as the propagation of the delamination is defined by the rate of damage is defined as:

$\frac{d}{d N} D=\frac{4.87 \times 10^{-6}}{L}\left(G_{\max }-G_{\min }\right)^{1.15}$

\section{Results and discussion}

General numerical solution procedure is to use a Newton-Raphson solution technique to solve the nonlinear system of equations. Other researchers [41-42] presented a Newton-Raphson solution technique to solve the nonlinear system of equations. Though, the Jacobian matrix is unsymmetrical and since is not suitable for FE. The overall procedure for static cohesive crack growth simulation is briefly shortlisted in the next steps: (1) solve the linear system of equations under the external load and calculate the external SIFs, then determine the crack growth; (2) let the damage parameter as a given constant parameter; (3) solve the nonlinear system of equilibrium Equations; (4) calculate the damage parameter under the current external loads for the present crack-tip opening; and (5) go to Step 2 and repeat the calculation for the next step. A quasi-static analysis approach is used for the current viscoelastic modeling. The accuracy of the analysis is controlled by the maximum difference between the creep strain at the beginning and the end of the increment given as

$\dot{\varepsilon}_{c r}(t+\Delta t)-\dot{\varepsilon}_{c r}(t) \leq 10^{-3}$

Fatigue failures in painting take place in cyclic loading, after a definite time. It also shows evidence of through-thickness and interfacial cracks in paintings under mechanical stresses, as well as the delamination between oil and acrylic paints [32]. Here a similar geometry of the experimental setup is used (see Figure 2b). Fig. 5 shows Von mises stress, as combination of other stress (sx, sy, txy ...). In Figure 5, the stress variation in the materials is displayed. Stress contours for various displacements $(0.4,1.8,4.5,6 \mathrm{~mm})$ are illustrated in Figure 5. The stress contour with the unit of $\mathrm{Pa}\left(\mathrm{N} / \mathrm{m}^{2}\right)$ has the highest values at the crack edge and under the loading place in the middle. The maximum stress across the layer is $250 \mathrm{~Pa}$ at the lowest displacement and throughout the highest displacement is more than $\mathrm{kPa}$. Although the stress has increased in both layers, the pressure drop in the painting is larger than the canvas. Since the stress in the painting layer is 2.5 times the stress in the canvas layer. As in the cohesive zone model, the strip plastic zone has cohesive traction equal to yield stress, it is clear to track it while crack propagates through the process in Figure 5. 


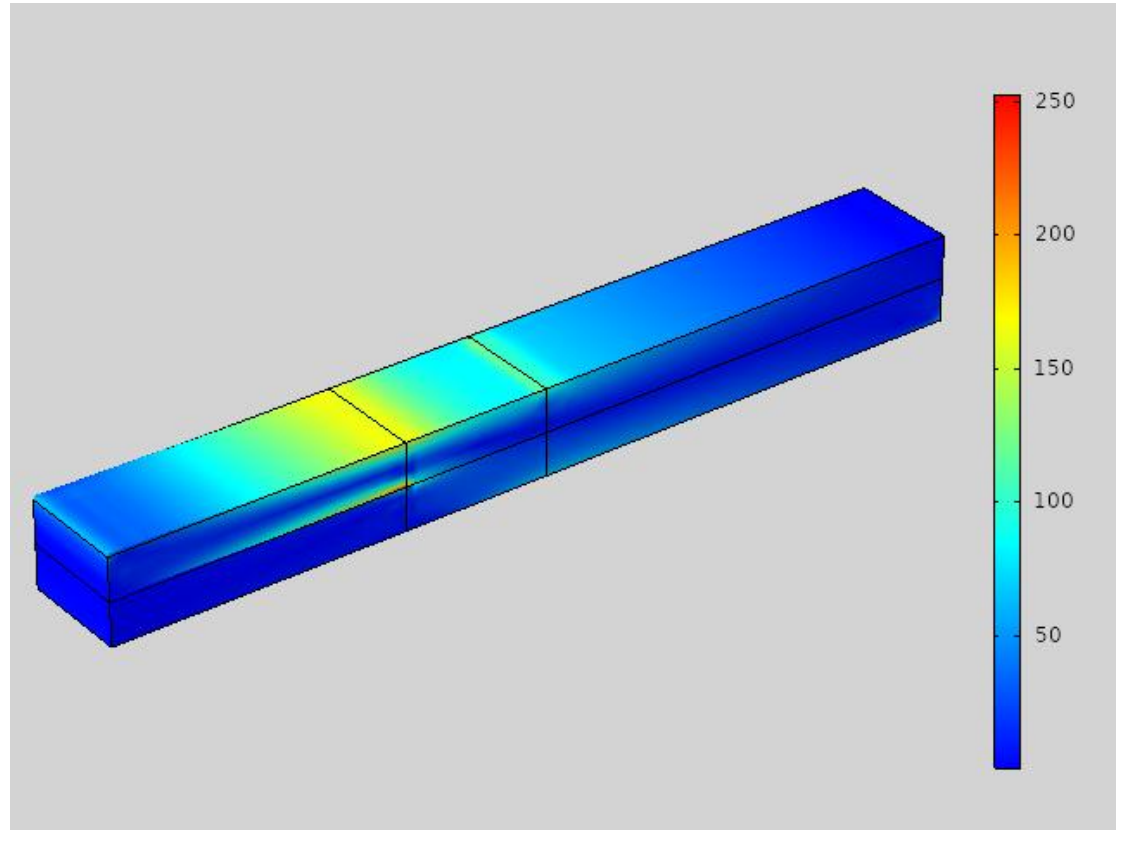

(a)

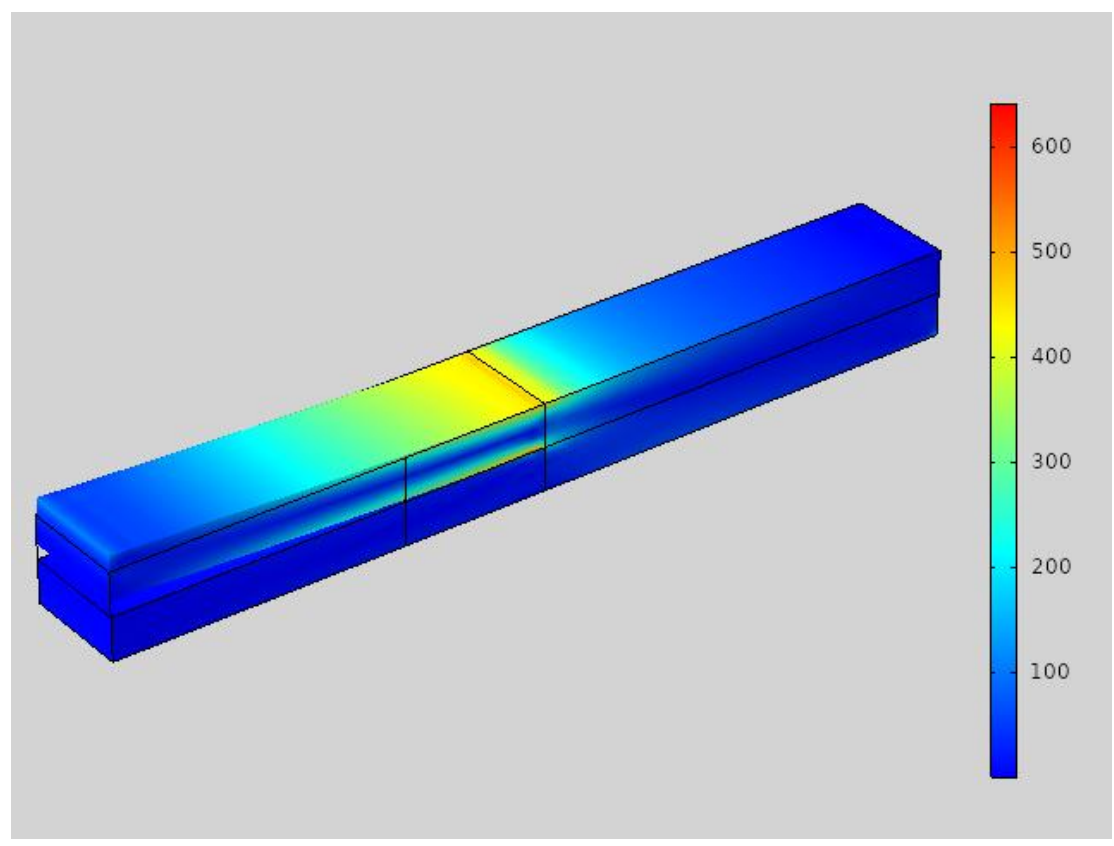




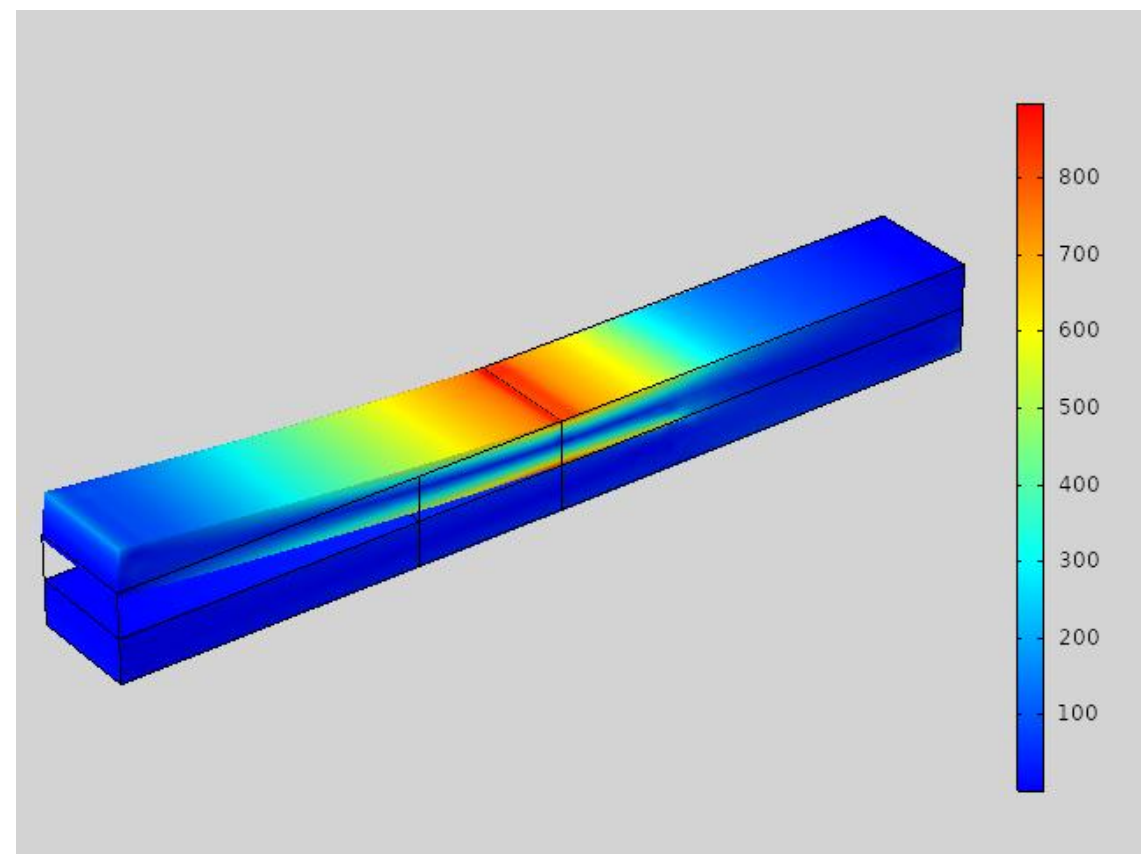

(c)

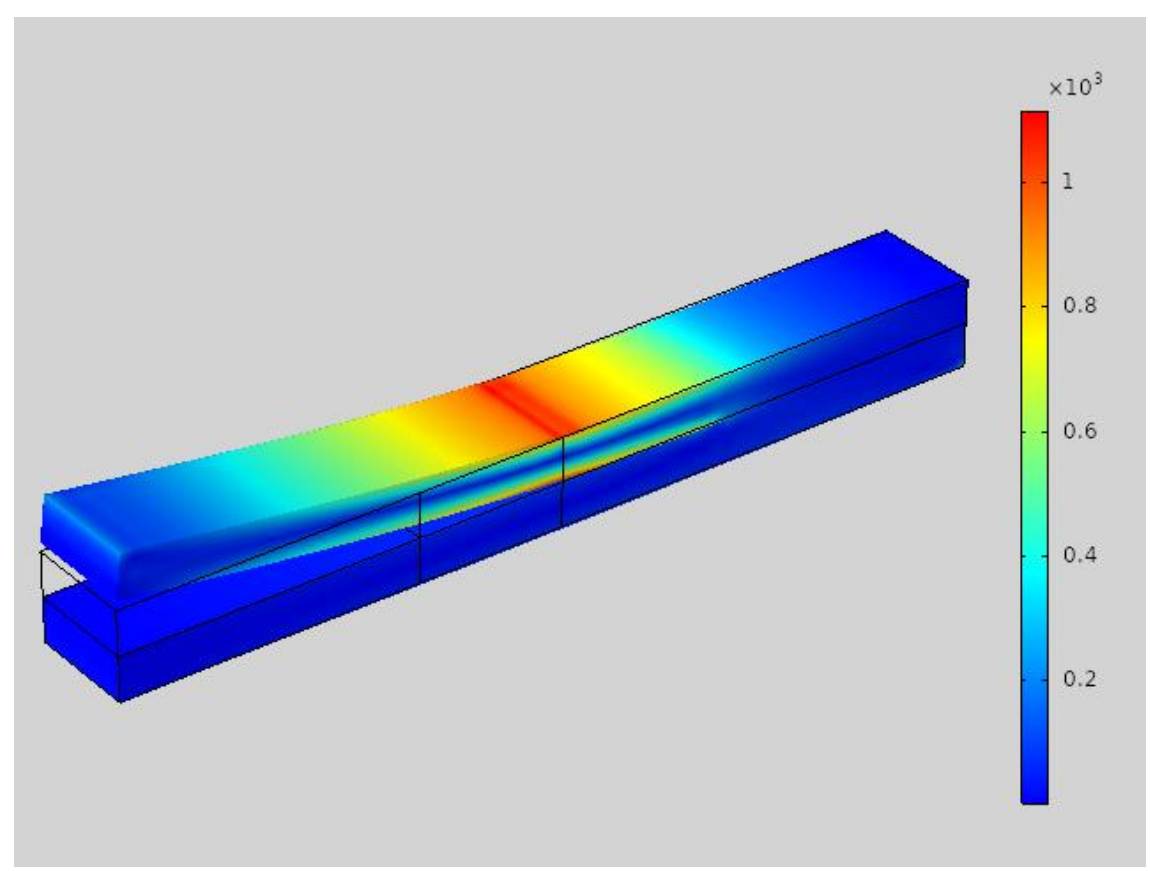

(d)

Figure 5. Von mises stress contours of a) 0.4, b)1.8, c) 4.5 , d) 6 displacement (mm).

As cohesive energy density defined by the integral of cohesive traction (or the closure stress) over displacement, the comprehensive separation of layers happens when the cohesive energy density reaches the critical value. Damage parameter defined here (see equation (17)) doesn't include the micro-damage accumulation, cracking, and deterioration on the micro-level (which is subjected to the influence of stochastic factors) and clearly shows the macroscopic fatigue crack propagation up to the final failure. In a cohesive zone model, inside the cohesive zone beyond the crack tip, it can be expected the intermolecular surface forces are constant (beyond zone is zero) or has Lennard-Jones shape. In Figure 6, the damage evolution in the materials is displayed. Damage contours for various displacements $(0.4,1.8,4.5,6 \mathrm{~mm})$ are illustrated in Figure 6 . The maximum damage across the layer is 1 . Although the damage region has enlarged versus displacement, the 
depth is not changed linearly. At a displacement of $0.4 \mathrm{~mm}$, damage initiated while at $4.5 \mathrm{~mm}$ reaches the mid-plane and at $6 \mathrm{~mm}$ reached the final displacement.

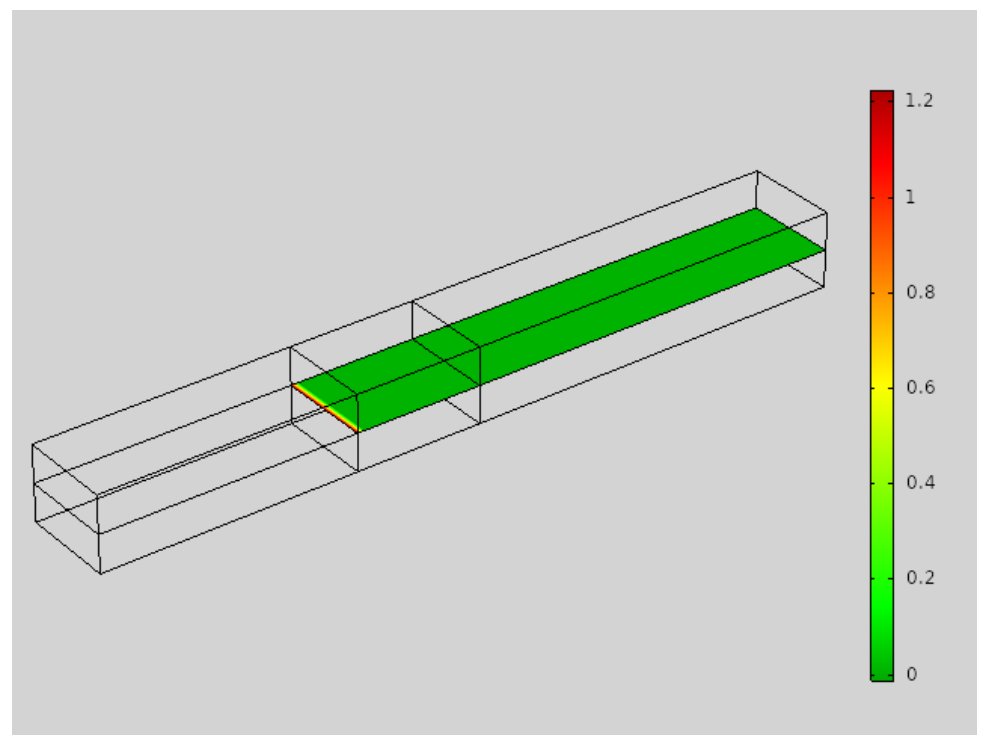

(a)

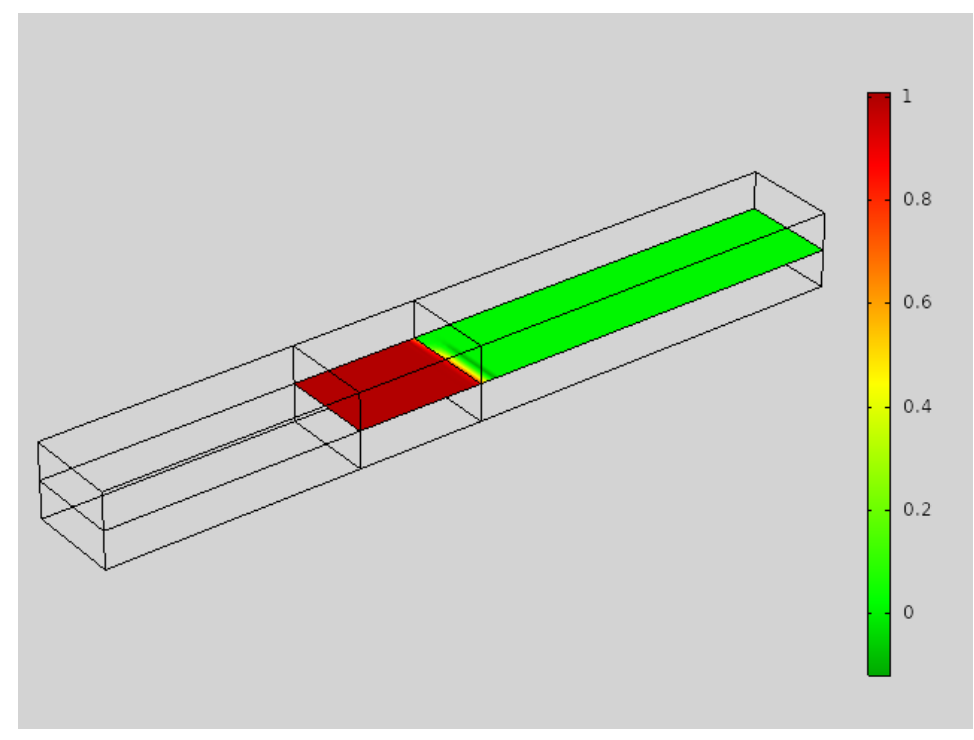




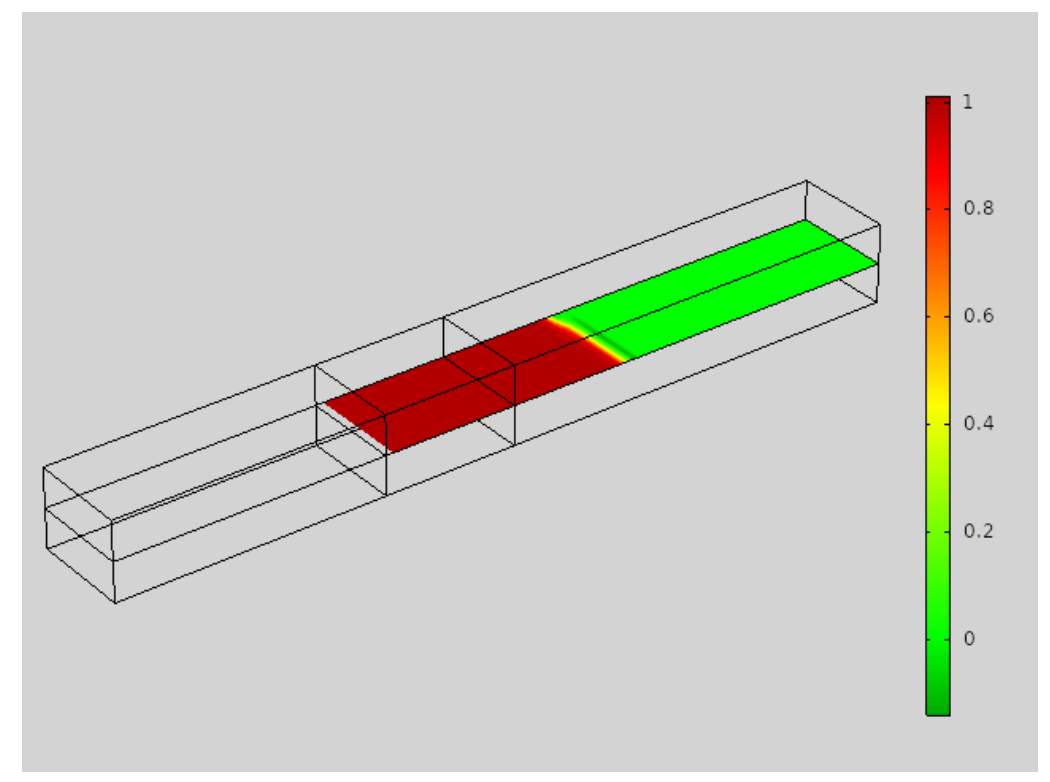

(c)

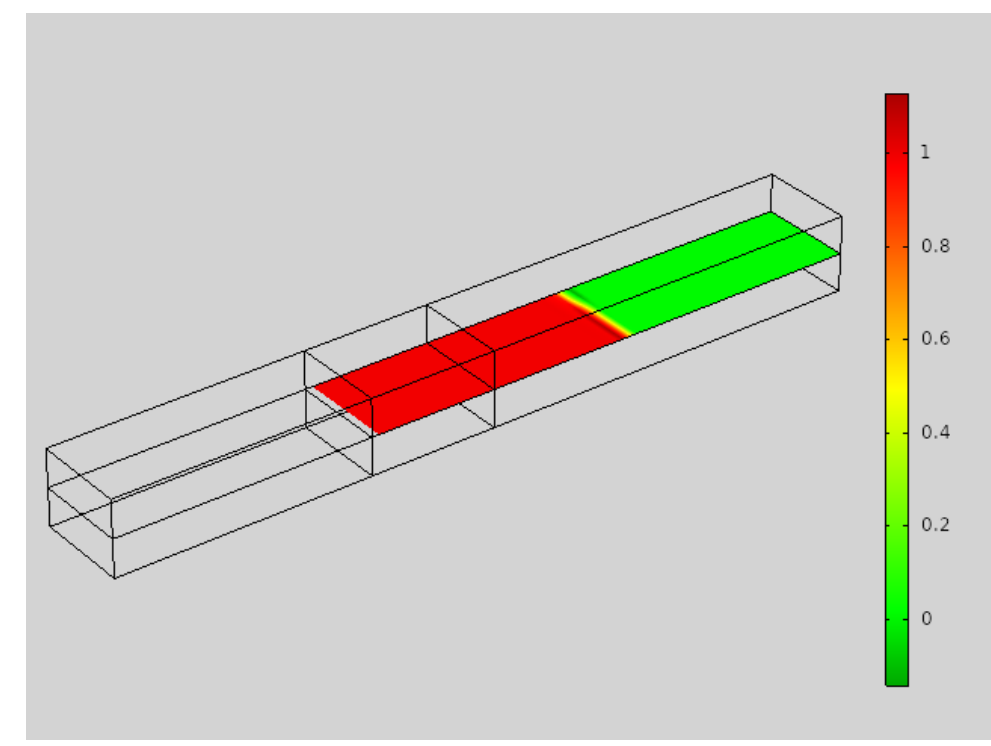

(d)

Figure 6. Damage evolution surface of a) 0.4 , b) 1.8 , c) 4.5 ,d) 6 displacement (mm).

The effect of painting layer thickness and initial crack length is revealed in Figure 7 . In Figure 7 a, the painting layer thickness is shown at $20^{\circ} \mathrm{C}$. Regarding the figure, the behavior of force-displacement is similar while the values are different. In contrast to low thickness cases, the increasing behavior of curves is observed after the initial displacement and the highest at the final displacement. In Figure $7 \mathrm{a}$, the thickness of the painting system is changed from $1 \mathrm{~mm}$ to $1 \mathrm{~cm}$. By increase of painting system's thickness, the value of maximum force increases. In Figure $7 \mathrm{~b}$, the painting layer thickness is shown at $20{ }^{\circ} \mathrm{C}$. Regarding the figure, the behavior of force-displacement is similar while the values are different. In all cases, the decreasing behavior of curves is observed after the initial displacement and the highest at the initial of damage displacement. In Figure $7 \mathrm{~b}$, the initial crack length of the painting system is changed from $2 \mathrm{~cm}$ to $4 \mathrm{~cm}$. By increase of painting system's initial crack length, the value of maximum force increases.

The curves in Fig. 7a ad 7b are not differ in character. As shown In 7a, the curves tend to increase further after minor drop, but $7 \mathrm{~b}$ shows no such increase. As seen the delta displacement, at which point is it measured. The applied force $\mathrm{F}$ is similar to the applied force from Fig. 2 and calculated from the location of crack tip. 


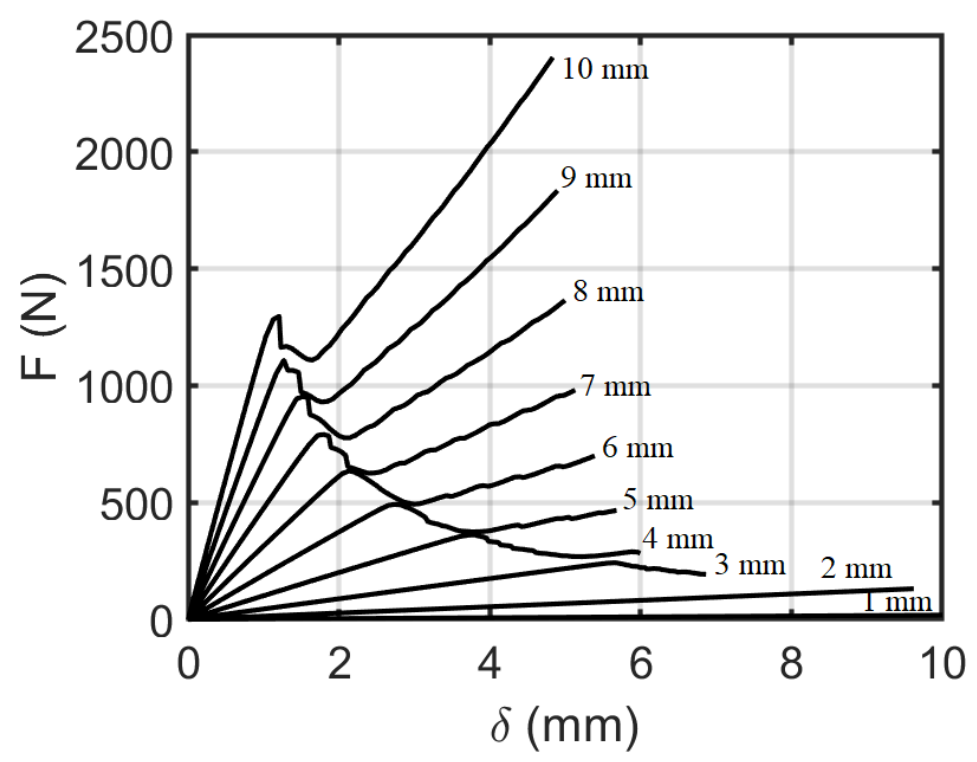

(a)

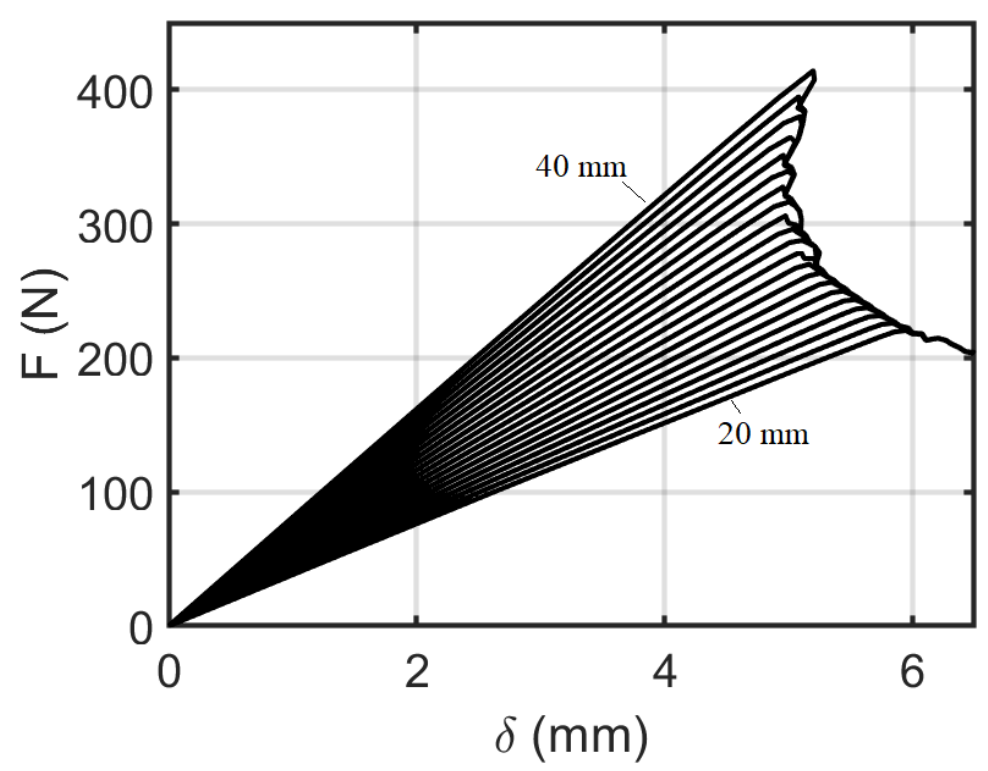

(b)

Figure 7. a) The effect of painting layer thickness, b) The effect of initial crack length.

The effects of temperature and relative humidity are considered within the external uniform load applied in the FEM. Figure 8 reveals the initiation time of delamination versus loading relative humidity percent at one cycle/day and loading temperature. For polymer coatings used in disposable products or household, the designated polymer would only be anticipated to last a few years, for cars and buildings around ten years. When the RH cycles have been resolved for the works of art, it is conceivable to actualize them as limited conditions. It has been recognized that on a quiet day the RH cycle is roughly sinusoidal and has a most extreme RH of 95\% RH at 06:00 in the first part of the day (min temp) and the base of 35\% RH at 15:00 toward the evening (max temp). In this manner, this sinusoidal cycle will be actualized with various min and max esteem to decide the impact on split inception time. In Figure 8 a, the initiation time of delamination versus loading relative humidity percent at one cycle/day is shown at $20{ }^{\circ} \mathrm{C}$. Regarding the figure, the behavior of life-loading is logarithmic. In Figure 8 a, the loading relative humidity percent at one cycle per day is changed from $10 \%$ to 50 $\%$. As illustrated by the increase of loading relative humidity percent at one cycle per day, the values of initiation time of delamination decrease. 
Although the physical parameters of materials may depend on the relative humidity and temperature, but here for simplicity they assumed as constant parameters. Irreversible Cohesive Zone Model does not require a Paris Law definition (required in direct cyclic fatigue method) is appropriate for both Mode-I and Mode-II fracture problems. The crack growth rate may be augmented in the real condition because of the accumulation of other issues such as chemical damage and temperature change. In Figure $8 \mathrm{~b}$, the painting time of crack initialization is shown at various temperatures loading. Total adhesive fracture energy is considered as $250 \mathrm{~N} / \mathrm{m}$. By observe on this figure, behavior of life-loading is logarithmic. Higher the strain rate, the higher the stiffness of the paints, and the higher the temperature, the lower the stiffness. In Figure $8 \mathrm{~b}$, the loading temperature at one cycle per day is changed from $10{ }^{\circ} \mathrm{C}$ to $30{ }^{\circ} \mathrm{C}$. As illustrated by the increase of loading temperature difference at one cycle per day, the values of initiation time of delamination decrease.

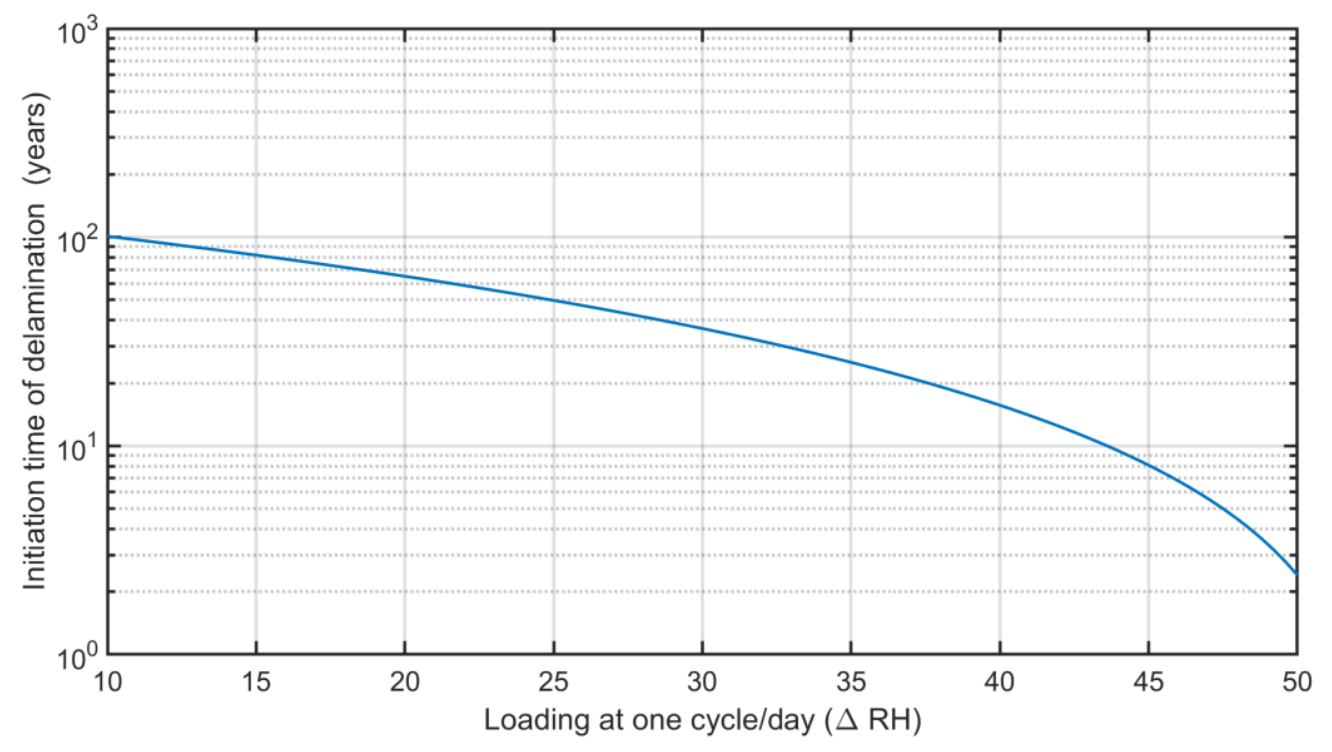

(a)

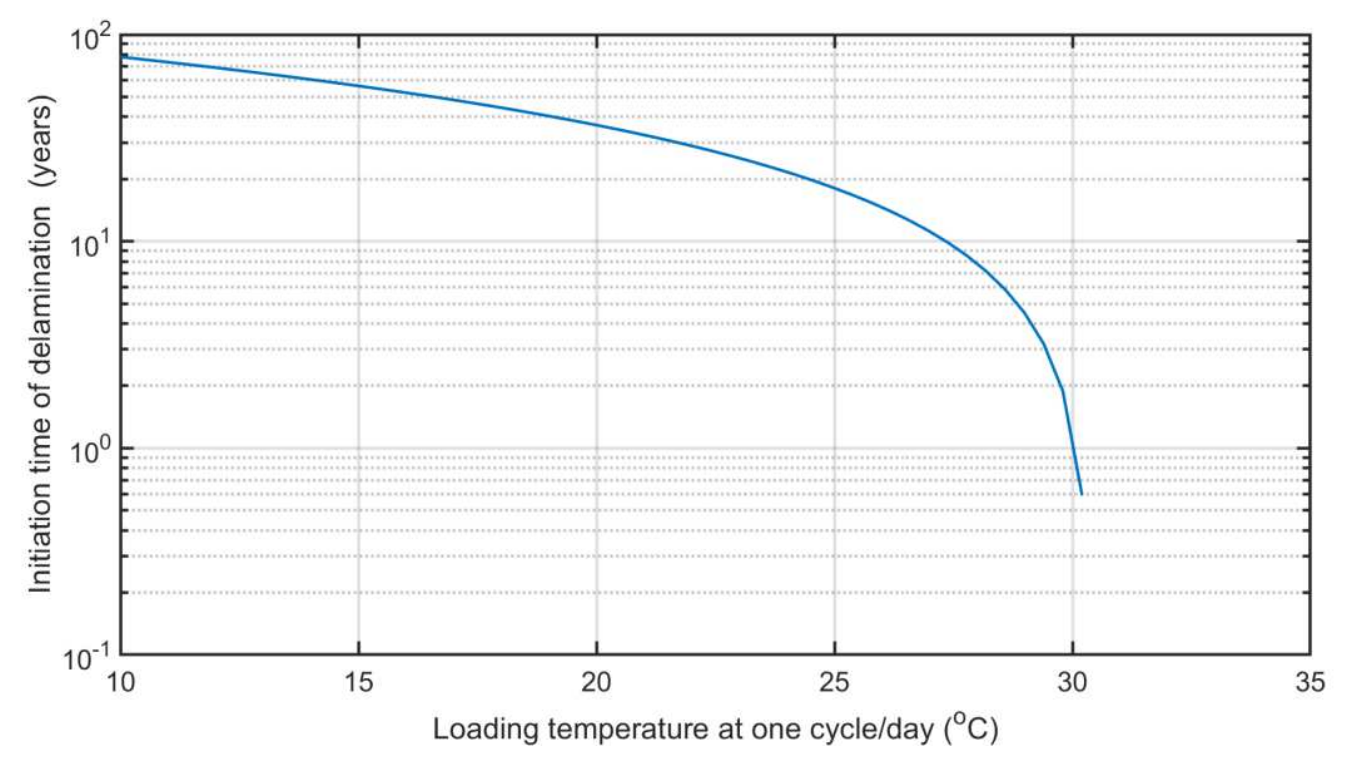

(b)

Figure 8. a) Initiation time of delamination versus loading relative humidity percent at one cycle/day, b) Initiation time of delamination versus loading temperature.

Fig. 9 which shows the force magnitude versus crack extension for various thickness and initial length assesses the geometrical effects. Each data point is obtained by recording the force when the cohesive element at the current crack tip is fully damaged; the crack is then considered to be extended by one element length. 
After the initiation, the relationship of the crack extension versus time is found to be approximately linear with a constant extension rate. This is small; highlighting that damage propagation in works of art is likely to be a slow process. Non-destructive inspections could reveal damage and timely corrective action could be taken to allow conservation of fine-art paintings.

Figure 9 shows the effect of crack length on maximum components of stress in numerical modeling of delamination. As shown the maximum stress happens in normal stress and shear stress is not important in this case. The shear stress in this test is lower than normal stress by two orders of magnitude. As the applied load made the system to bend, the produced stress field is anticipated. As shown normal stress (in beam axial direction) is in order of von misses stress.

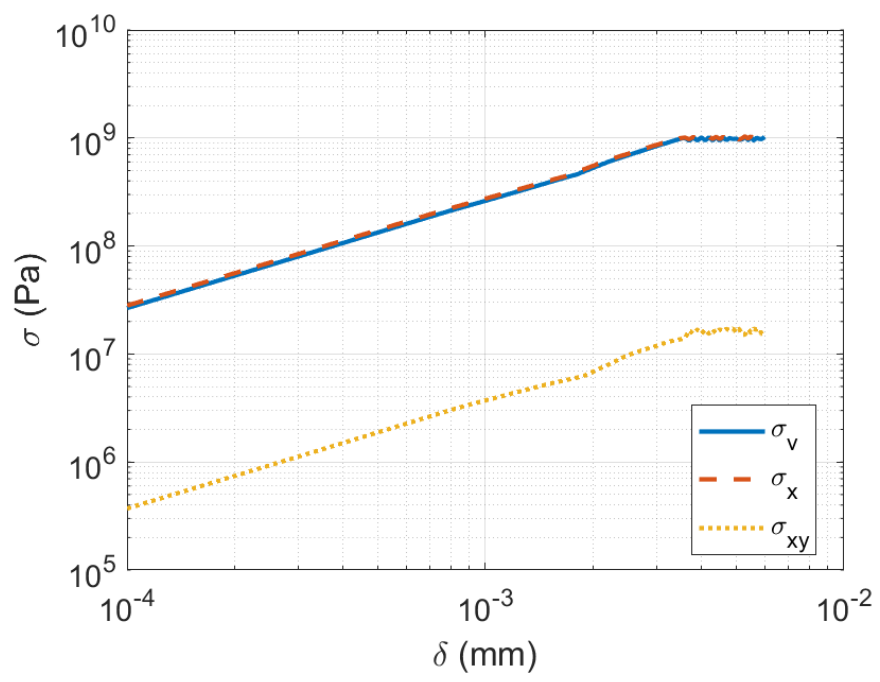

Figure 9. Comparison of various components of stress.

\section{Conclusions}

In this research, by use of the irreversible cohesive zone model, the effect of temperature and relative humidity cycles on multilayer thin-film paintings is investigated. Tensile and delamination properties of the paints are used for the finite element simulation of the fatigue life prediction model. The homogenous one-dimensional paint layers composed of alkyd and acrylic gesso over a canvas foundation (support) with known constant thicknesses are considered as the mechanical model of painting. Experimental data used for mathematical modeling of canvas as a linear elastic material and paint as a viscoelastic material with the Prony series. Two types of crack through the length and width of the paint layers are modeled by cyclic mechanical loadings. The three-dimensional modeling of the system is solved by the finite element method in a plane strain formulation. Fatigue damage parameters such as crack initiation time and maximum loads are calculated by an irreversible cohesive zone model under low-cycle fatigue caused by temperature and relative humidity cycles. As shown:

- $\quad$ By increase of painting system's thickness, the value of maximum force increases.

- By increase of painting system's initial crack length, the value of maximum force increases.

- By increase of loading relative humidity percent at one cycle per day, the values of initiation time of delamination decrease.

- By increase of loading temperature difference at one cycle per day, the values of initiation time of delamination decrease.

The advantages of the present work is to calculate the crack length propagation in painting layers and limitation is constant coefficients. To continue this research the author suggests making accelerated fatigue delamination by humidity and temperature-controlled chamber. The material age, anisotropic behavior of the canvas, are also other parameters that are neglected in the current paper. Finally, the inverse analysis can be employed to optimize the coating design.

\section{Nomenclature}


A peel arm cross-sectional area

$378 \quad \mathrm{~A}_{0}$ sample's original cross-sectional area

379 a crack length

380 b peel arm width

381 C experimental constant for Paris' Law equation

382 D damage parameter

383 E Young's elastic modulus

384 f nominal stress-stretch function

385 G energy release rate

$386 \mathrm{G}_{\mathrm{c}}$ adhesive fracture energy of a peel arm

$387 \quad \mathrm{G}_{\mathrm{p}}$ local plastic/viscoelastic work done per unit area

388 g Prony series non-dimensional parameter

$389 \mathrm{~g}_{\mathrm{e}} \quad$ Prony series equilibrium term

$390 \mathrm{~h}$ peel arm thickness

$391 \quad h_{c} \quad$ width of the fracture front

392 I first stretch invariant

393 K stress intensity factor

394 L element characteristic length

$395 \quad \mathrm{~L}_{0} \quad$ sample's original length

396 m experimental constant for Paris' Law equation

397 M number of terms in Prony series

$398 \quad$ P applied load

$399 \mathrm{~T}$ temperature

$400 \quad t_{n}$ normalized time

$401 \quad$ W strain energy potential

$402 \alpha$ chain interaction parameter in van der Waals time-independent material parameters

$403 \quad \beta_{\text {eff }}$ hygrothermal expansion coefficient

$404 \delta \quad$ crack displacement, separation, displacement parameter

$405 \varepsilon_{\mathrm{x}, \mathrm{y}, \mathrm{z}}$ principal strains 
$\lambda \quad$ stretch ratio

$\lambda_{\mathrm{m}} \quad$ locking stretch

$408 \mu \quad$ initial Shear Modulus

$409 \quad \sigma_{x, y, z} \quad$ principal stress

$410 \quad v \quad$ Poisson's ratio

\section{Competing interests}

412 The author declare that they have no competing interests.

\section{$413 \quad$ Funding}

414 Current research is partially funded by NAWA project number PPN/PPO/2018/1/00004/U/00001.

\section{References}

416 1. Rice, J. Elastic fracture mechanics concepts for interfacial cracks. J. Appl. Mech. 55(1988): 98-103.

417 2. Bank-Sills, L., N. Travitzky, D. Ashkenazi and R. Eliasi A methodology for measuring interface fracture properties of 418 composite materials. Int. J. Fracture. 99(1999): 143-161.

3. Charalambides, P., J. Lund, A. Evans and R. McMeeking A test specimen for determining the fracture resistance of bimaterial interfaces. J. Appl. Mech. 56(1989): 77-82.

4. Tippur, H. V. and S. Ramaswamy Measurement of mixed-mode fracture parameters near cracks in homogeneous and bimaterial beams. Int. J. Fracture. 61(1993): 247-265.

5. Slowik, V., J. C. Kishen and V. E. Saouma Mixed mode fracture of cementitious bimaterial interfaces: Part I Experimental results. Eng. Fract. Mech. 60(1998): 83-94.

6. Kotousov, A., F. Berto, P. Lazzarin and F. Pegorin Three dimensional finite element mixed fracture mode under anti-plane loading of a crack. Theor. Appl. Fract. Mec. 62(2012): 26-33.

7. Kotousov, A., P. Lazzarin, F. Berto and L. Pook Three-dimensional stress states at crack tip induced by shear and anti-plane loading. Eng. Fract. Mech. 108(2013): 65-74.

8. Pook, L. P., A. Campagnolo, F. Berto and P. Lazzarin Coupled fracture mode of a cracked plate under anti-plane loading. Eng. Fract. Mech. 134(2015): 391-403.

9. Červenka, J., J. C. Kishen and V. E. Saouma Mixed mode fracture of cementitious bimaterial interfaces: Part II numerical simulation. Eng. Fract. Mech. 60(1998): 95-107.

10. Moës, N. and T. Belytschko Extended finite element method for cohesive crack growth. Eng. Fract. Mech. 69(2002): 813-833.

11. Yang, Z. and A. Deeks Fully-automatic modelling of cohesive crack growth using a finite element-scaled boundary finite element coupled method. Eng. Fract. Mech. 74(2007): 2547-2573.

12. Dong, W., Z. Wu and X. Zhou Calculating crack extension resistance of concrete based on a new crack propagation criterion. Constr. Build. Mater. 38(2013): 879-889.

13. Wu, Z., H. Rong, J. Zheng and W. Dong Numerical method for mixed-mode I-II crack propagation in concrete. J. Eng. Mech. 139(2013): 1530-1538.

14. Wang, C., Z. Zhu and H. Liu On the I-II mixed mode fracture of granite using four- point bend specimen. Fatigue Fract. Eng. M. 39(2016): 1193-1203.

15. Gómez, F., M. Elices, F. Berto and P. Lazzarin Local strain energy to assess the static failure of U-notches in plates under mixed mode loading. Int. J. Fracture. 145(2007): 29-45.

16. Z. P. Bažant, Yuan-Neng Li,Stability of Cohesive Crack Model: Part I-Energy Principles,J. Appl. Mech. 1995, 62(4): 959-964

17. Wu Xua Anthony, M.Waas, Modeling damage growth using the crack band model; effect of different strain measures, Engineering Fracture Mechanics, 152, 2016, 126-138

18. Y. Jenq, S.P. Shah, Two parameter fracture model for concrete, J Eng Mech, 111 (1985), pp. 1227-1241 
19. S.L. Xu, H.W. Reinhardt, Determination of double-K criterion for crack propagation in quasi-brittle fracture, Part II: analytical evaluating and practical measuring methods for three-point bending notched beams, Int J Fract, 98 (1999), pp. 151-177

20. Kumar S., Barai S.V. Crack Propagation Study Using Double-K and Double-G Fracture Parameters. In: Concrete Fracture Models and Applications(2011). Springer, Berlin, Heidelberg

Gómez, F., M. Elices, F. Berto and P. Lazzarin Fracture of U-notched specimens under mixed mode: experimental results and numerical predictions. Eng. Fract. Mech. 76(2009): 236-249.

17. Berto, F., P. Lazzarin, F. Gómez and M. Elices Fracture assessment of U-notches under mixed mode loading: two procedures based on the 'equivalent local mode I' concept. Int. J. Fracture. 148(2007): 415-433.

18. Gómez, F., M. Elices, F. Berto and P. Lazzarin Fracture of V-notched specimens under mixed mode (I+ II) loading in brittle materials. Int. J. Fracture. 159(2009): 121-135.

19. Lazzarin, P., F. Berto, M. Elices and J. Gómez Brittle failures from U- and V- notches in mode I and mixed I + II mode: a synthesis based on the strain energy density averaged on finite- size volumes. Fatigue Fract. Eng. M. 32(2009): 671-684.

20. $\mathrm{Mu}, \mathrm{F}$. and J. Vandenbossche A superimposed cohesive zone model for investigating the fracture properties of concrete-asphalt interface debonding. Fatigue Fract. Eng. M. (2016) doi: 10.1111/ffe.12509.

21. Xu, S. and H. Reinhardt Determination of double-K criterion for crack propagation in quasi-brittle fracture: Part I Experimental investigation of crack propagation. Int. J. Fracture. 98(1999): 111-149.

22. Xu, S. and H. Reinhardt Determination of double-K criterion for crack propagation in quasi-brittle fracture: Part II Analytical evaluating and practical measuring methods for three-point bending notched beams. Int. J. Fracture. 98(1999): 151-177.

23. Nagashima, T., Y. Omoto and S. Tani Stress intensity factor analysis of interface cracks using X- FEM. Int. J. Numer. Meth. Eng. 56(2003): 1151-1173.

24. Dong, W., Z. Wu and X. Zhou Fracture mechanisms of rock-concrete interface: experimental and numerical. J. Eng. Mech. (2016) 04016040.

25. RILEM Determination of the fracture energy of mortar and concrete by means of three-point bend tests on notched beams. Mater. Struct. 18(1985): 285-290.

26. Dong, W., L. Zhang and Z. Wu Experiment study on tension softening constitutive relation of rock-concrete interface. J. Hydraul. Eng. 45(2014): 712-719.

27. Camanho, P.P. Davila, C.G. and De Moura, M.F., Numerical Simulation of Mixedmode Progressive Delamination in Composite Materials., Journal of composite materials 37.16 (2003): 1415-1438.

28. Reeder, J.R. , Crews Jr., J.R., Mixed-mode bending method for delamination testing., AiAA Journal 28.7 (1990): $1270-1276$.

29. E.W.S. Hagan, M.N. Charalambides, C.R.T. Young, T.J.S. Learner, S. Hackney, Tensile properties of latex paint films with TiO2 pigment, J Mech Time-Dependent Mater, 13 (2009), pp. 149-161

30. Tantideeravit S., Charalambides,M.N., Balint,D.S., Young, C.R.T.. Prediction of delamination in multilayer artist paints under low amplitude fatigue loading, Engineering Fracture Mechanics, Elsevier Ltd (2013), pp. 41-57

31. H.F. Enderle, H.G. Kilian, General deformation modes of a van der Waals network, Prog Colloid Polym Sci, 75 (1987), pp. 55-61

32. Mecklenburg Marion F., Determining the acceptable ranges of relative humidity and temperature in museums and galleries: Part 1, Structural Response to Relative Humidity, Smithsonian Museum Conservation Institute. (2007), pp. $1-57$

33. Keck S., Mechanical Alteration of the Paint Film, Studies in Conservation, 14 (1) (1969), pp. 9-30

34. Young C.R.T., Interfacial Interaction of Modern Paint Layers, Modern Paints Uncovered Symposium (2007), London, UK, 16-19 May 2006, pp. 247-25

35. Ning, J. \& Liang, S.Y. , Inverse identification of Johnson-Cook material constants based on modified chip formation model and iterative gradient search using temperature and force measurements, Int J Adv Manuf Technol (2019) 102: 2865-2876.

36. Ning, J., Nguyen, V., Huang, Y.., Karl T. Hartwig, Steven Y. Liang, Inverse determination of Johnson-Cook model constants of ultra-fine-grained titanium based on chip formation model and iterative gradient search, Int $\mathbf{J}$ Adv Manuf Technol (2018) 99: 1131-1140.

37. Jamalabadi, M.Y.A., Thermal Radiation Effects on Creep Behavior of the Turbine Blade, Multidiscipline Modeling in Materials and Structures 12 (2), 291-314 
38. M.L. Benzeggagh, M. Kenane, Measurement of mixed-mode delamination fracture toughness of unidirectional glass/epoxy composites with mixed-mode bending apparatus, Compos Sci Technol, 56 (1996), pp. 439-449

39. G.I. Barenblatt (1962). The mathematical theory of equilibrium cracks in brittle fracture. Advances in Applied Mechanics. 7. pp. 55-129.

40. Donald S. Dugdale (1960). Yielding of steel sheets containing slits. Journal of the Mechanics and Physics of Solids. 8 (2): 100-104.

41. Zhang, X. and Bui, T.Q. (2015), A fictitious crack XFEM with two new solution algorithms for cohesive crack growth modeling in concrete structures, Engineering Computations, Vol. 32 No. 2, pp. 473-497.

42. Wells, G.N. and Sluys, L.J. (2001),A new method for modelling cohesive cracks using finite elements, International Journal for Numerical Methods in Engineering, Vol. 50 No. 12, pp. 2667-2682. 
Figures

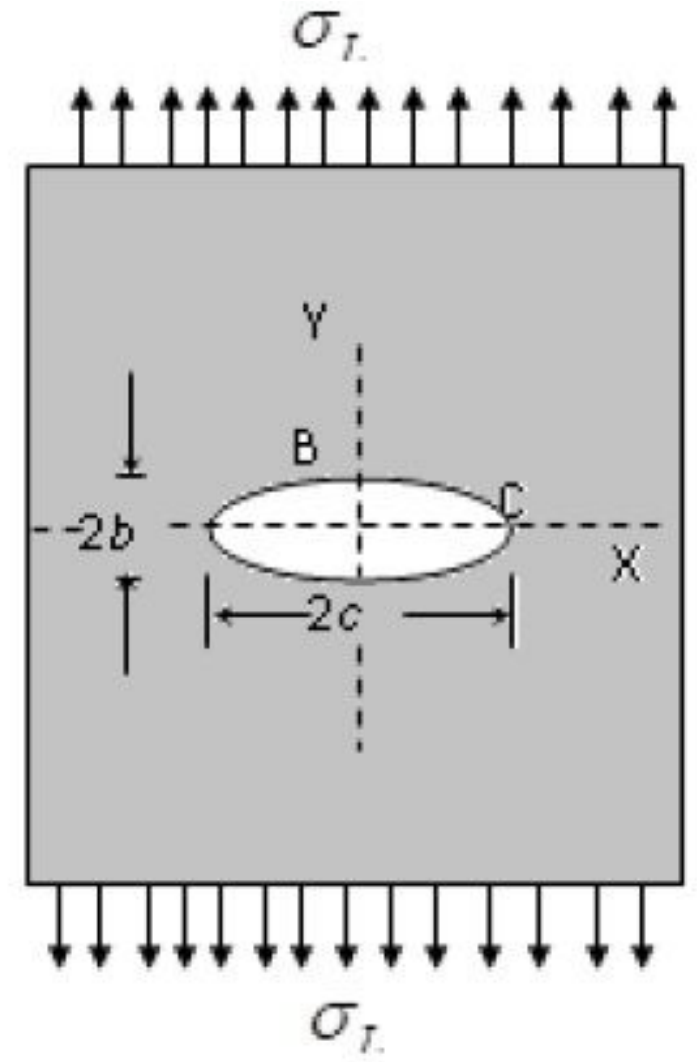

Figure 1

Schematic of 2D plane stress problem of a plate having the elliptical hole. 




a)



b)

Figure 2

a) schematic of the computational domain and boundary conditions. b) Schematic of the experimental 

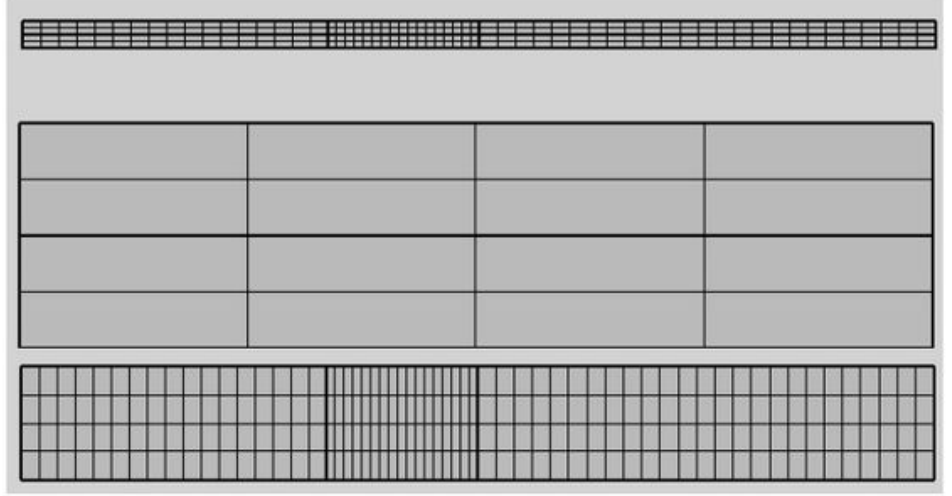

(a)

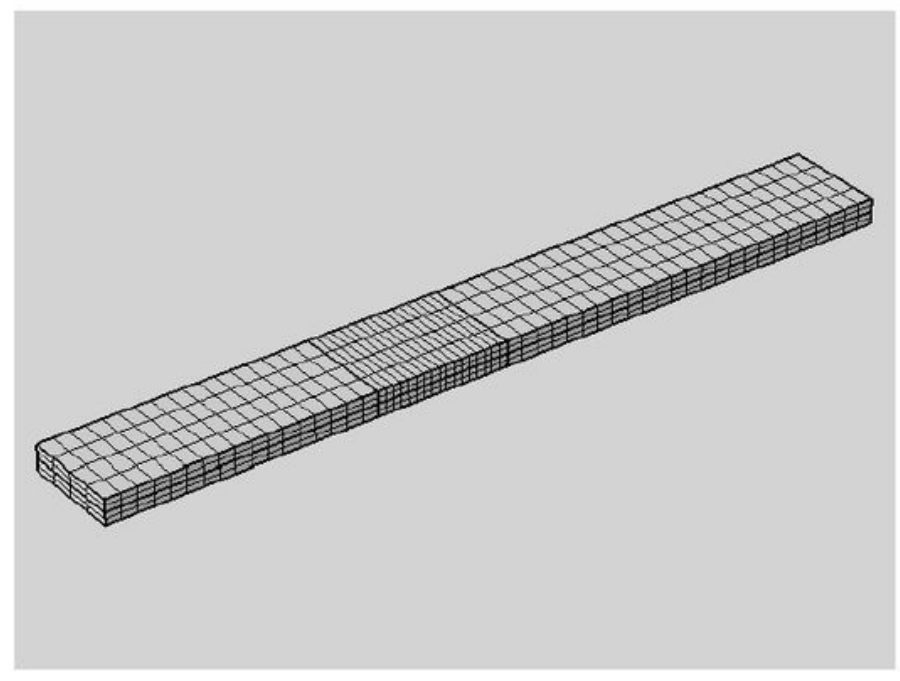

(b)

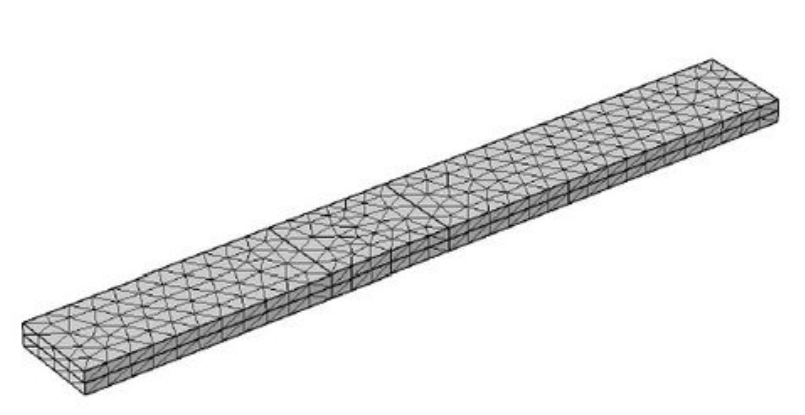

(c)

\section{Figure 3}

Multi-grid mesh for two layers (a) top view, right view, and front view (b) isometric view (c) irregular meshes. 


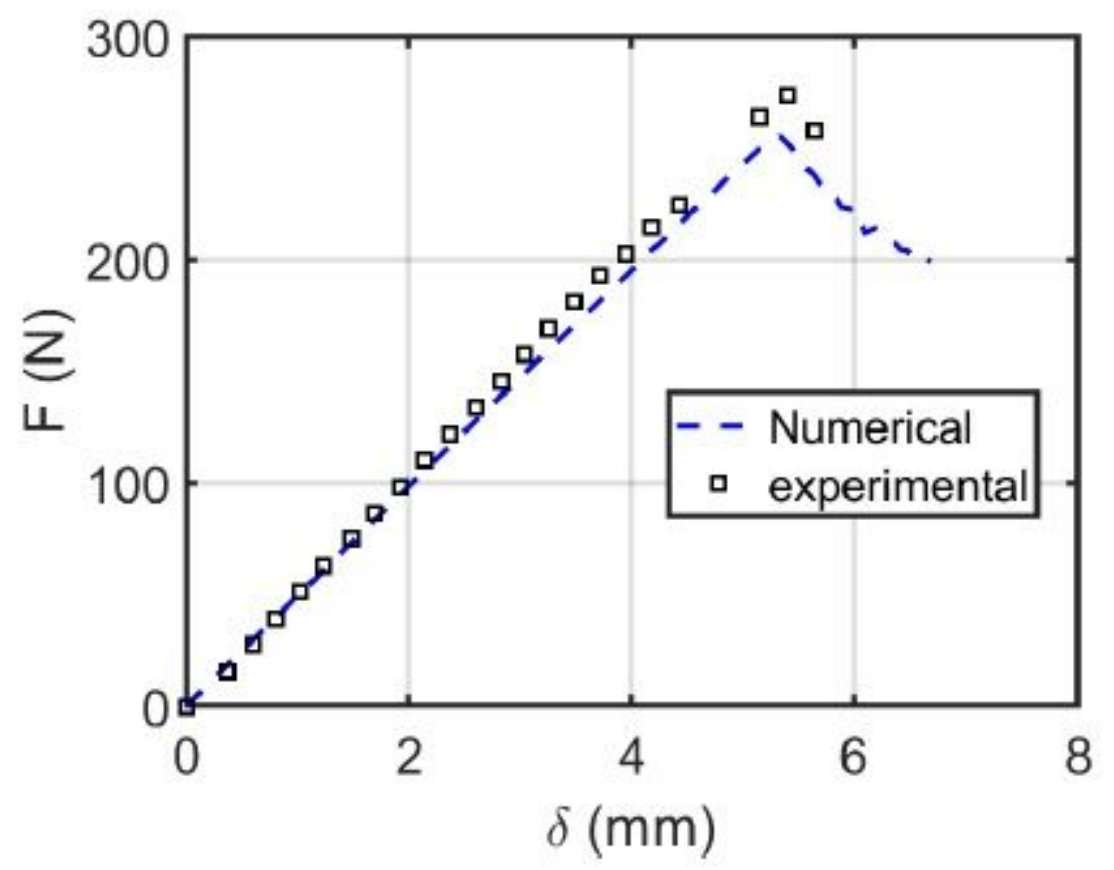

Figure 4

Comparison between the numerical simulation results and the experimental study by Camanho et al [27]. 


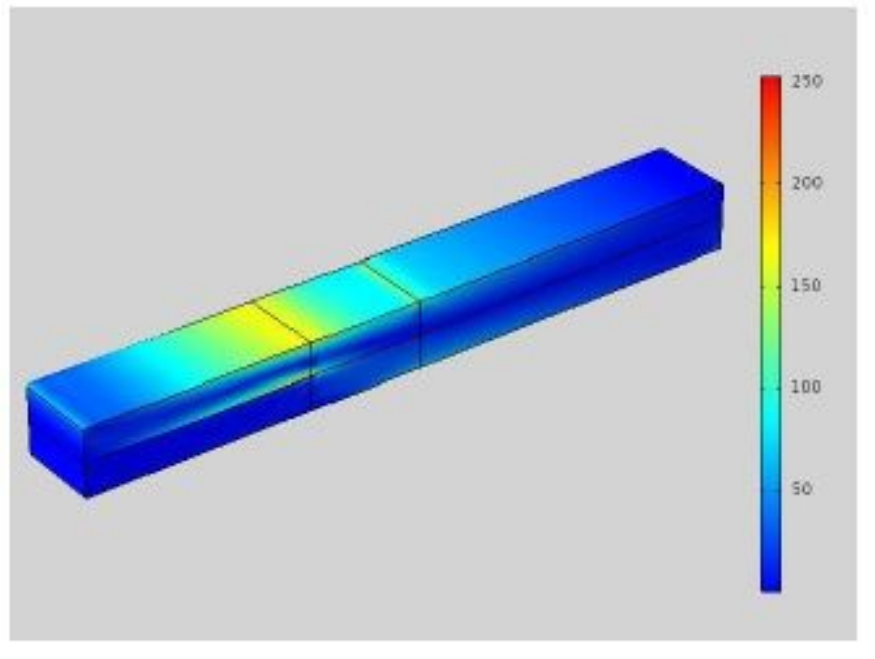

(a)

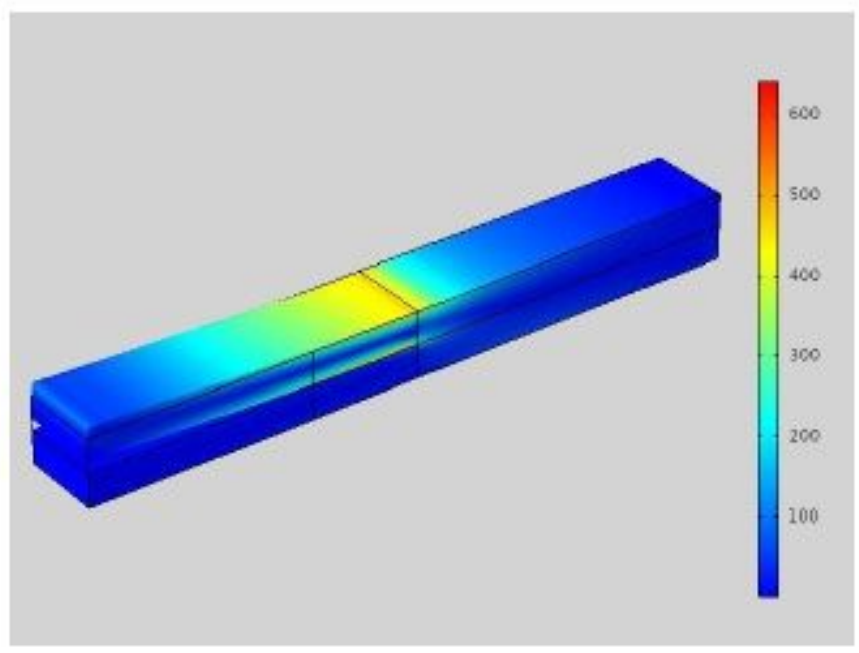

(b)

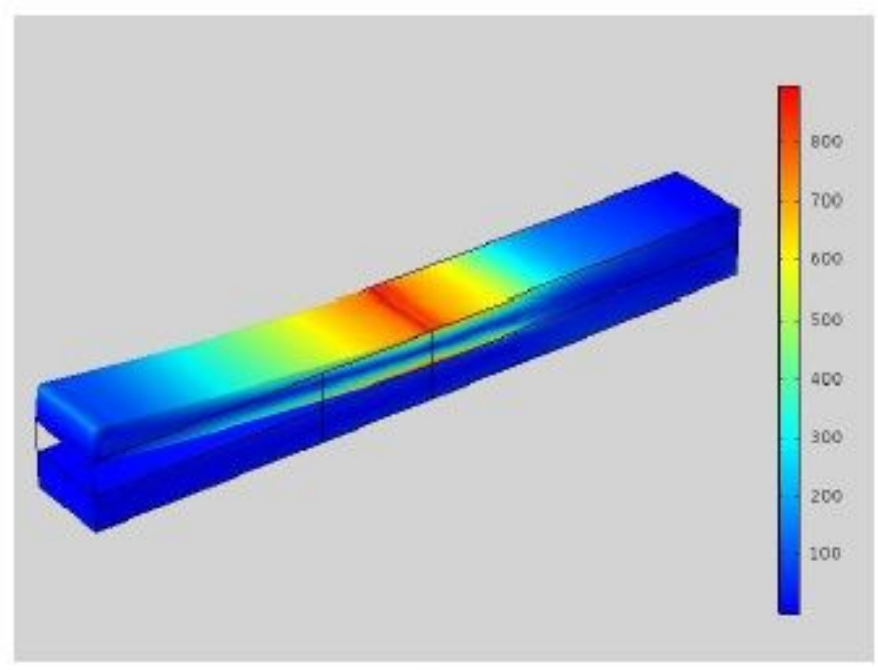

(c)

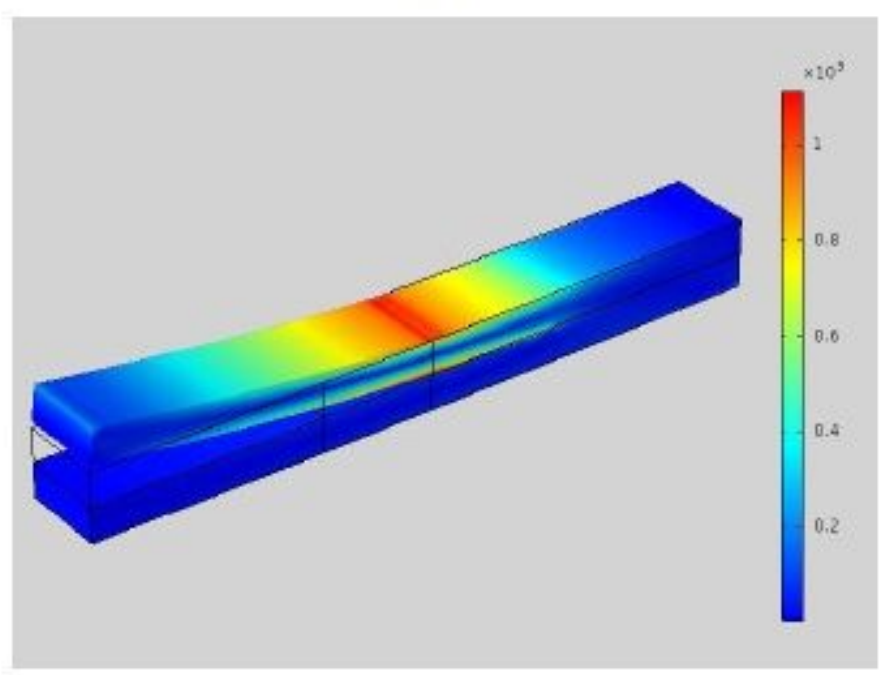

(d)

Figure 5

Von mises stress contours of a) 0.4, b) 1.8, c)4.5, d) 6 displacement (mm). 


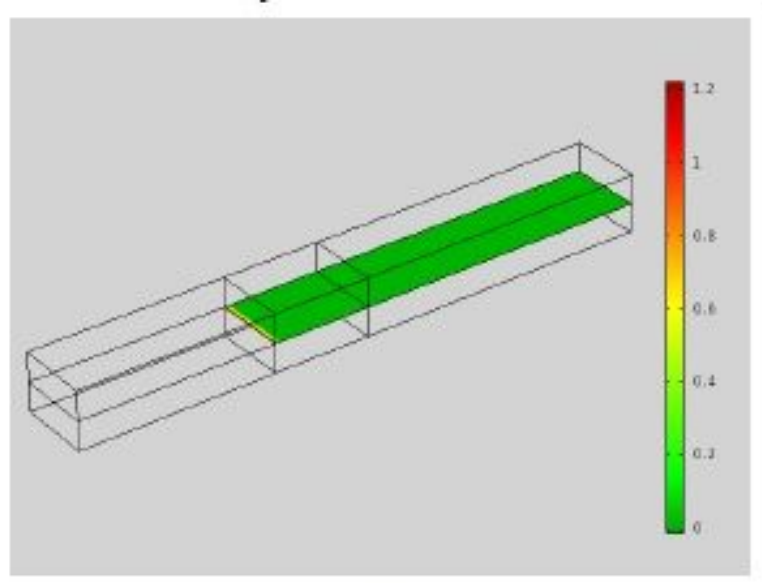

(a)

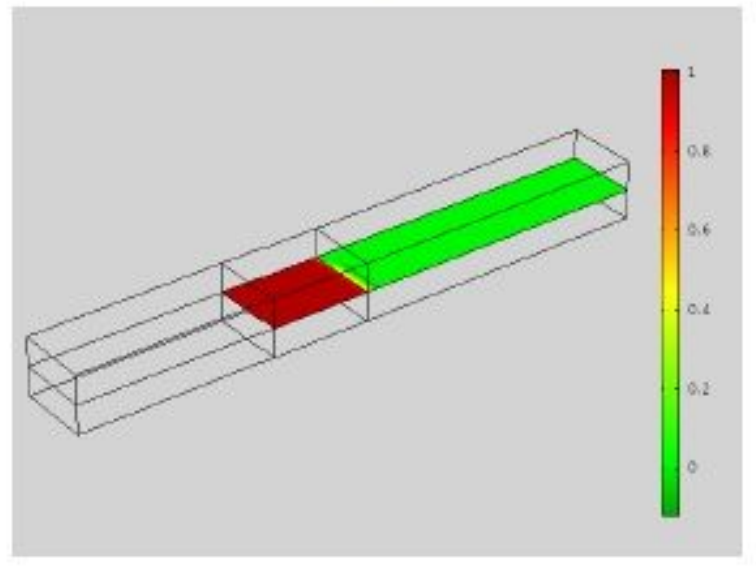

(b)

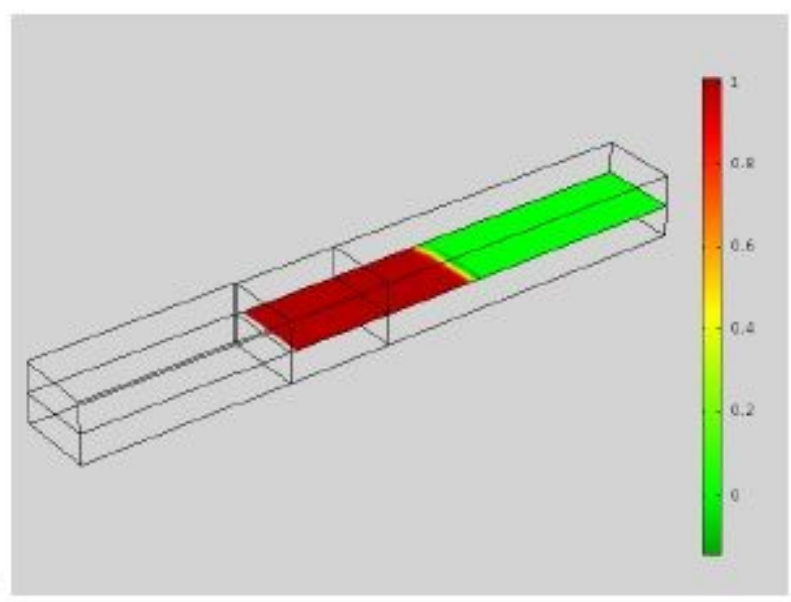

(c)

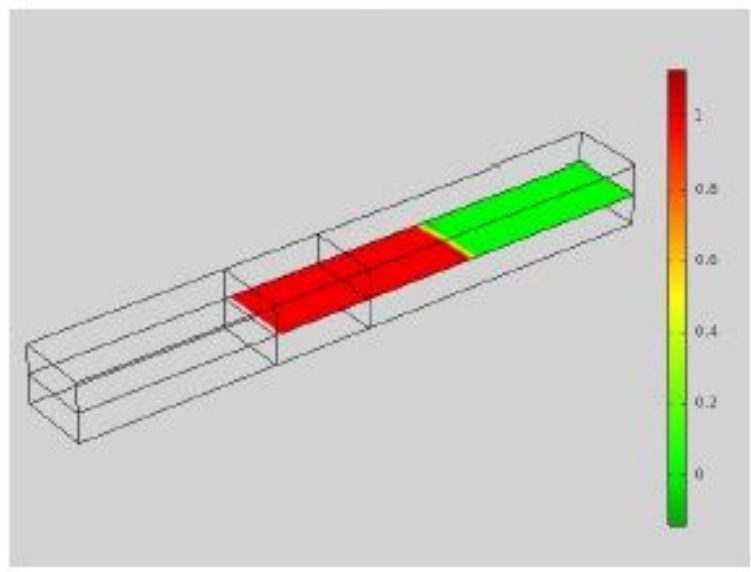

(d)

Figure 6

Damage evolution surface of a) 0.4, b) 1.8, c) 4.5 ,d) 6 displacement (mm). 


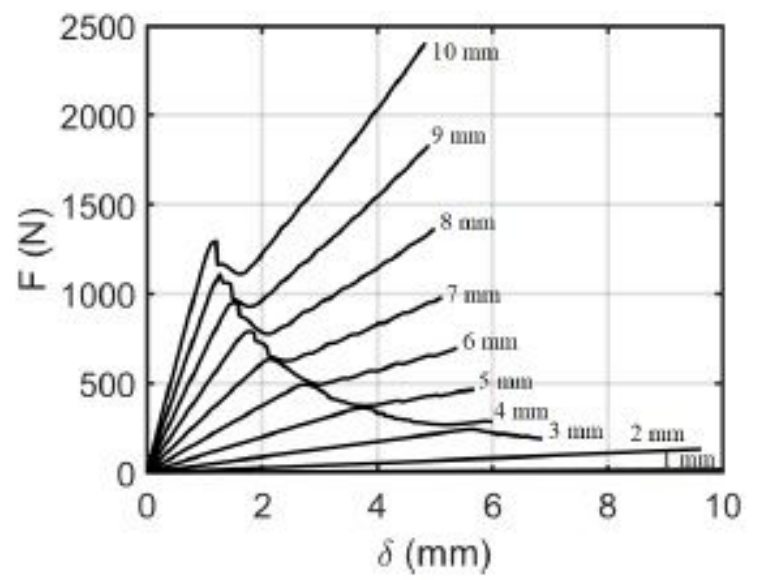

(a)

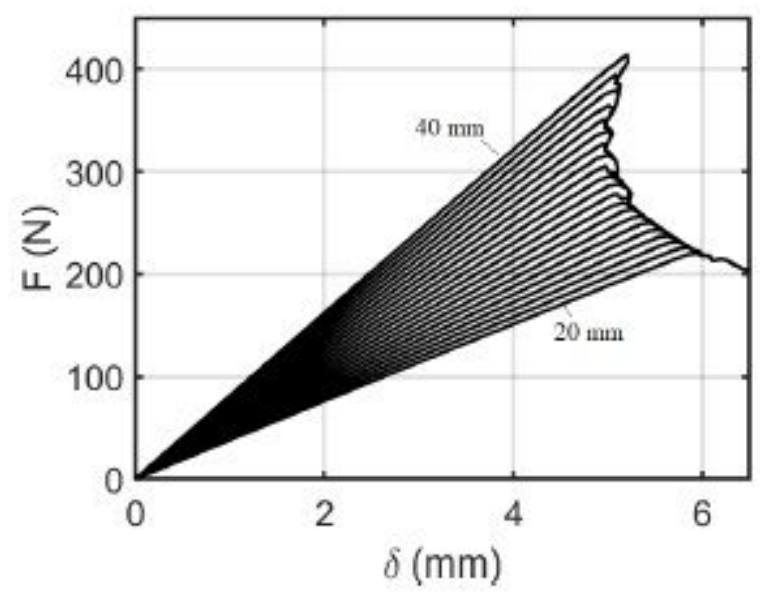

(b)

Figure 7

a) The effect of painting layer thickness, b) The effect of initial crack length 


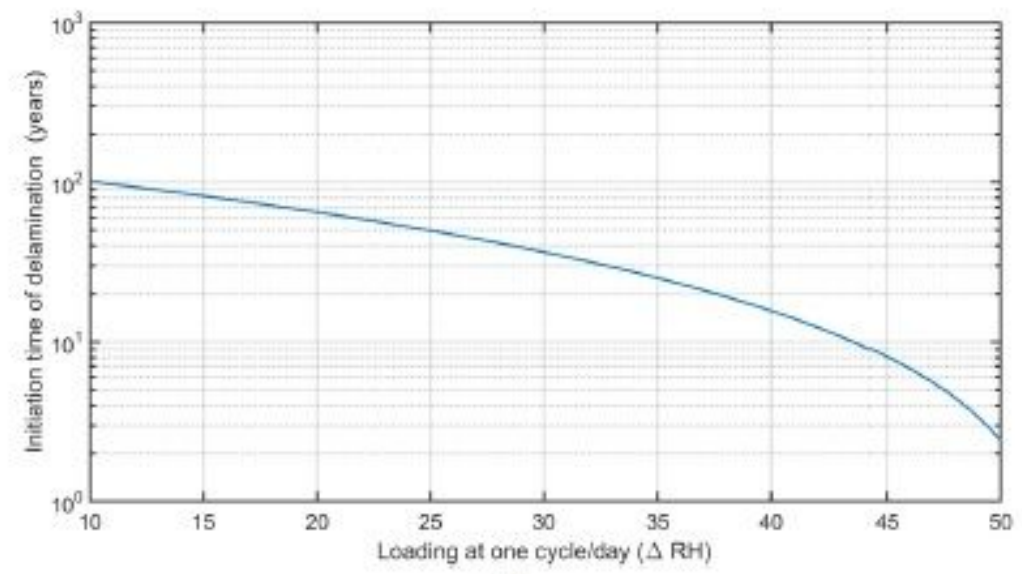

(a)

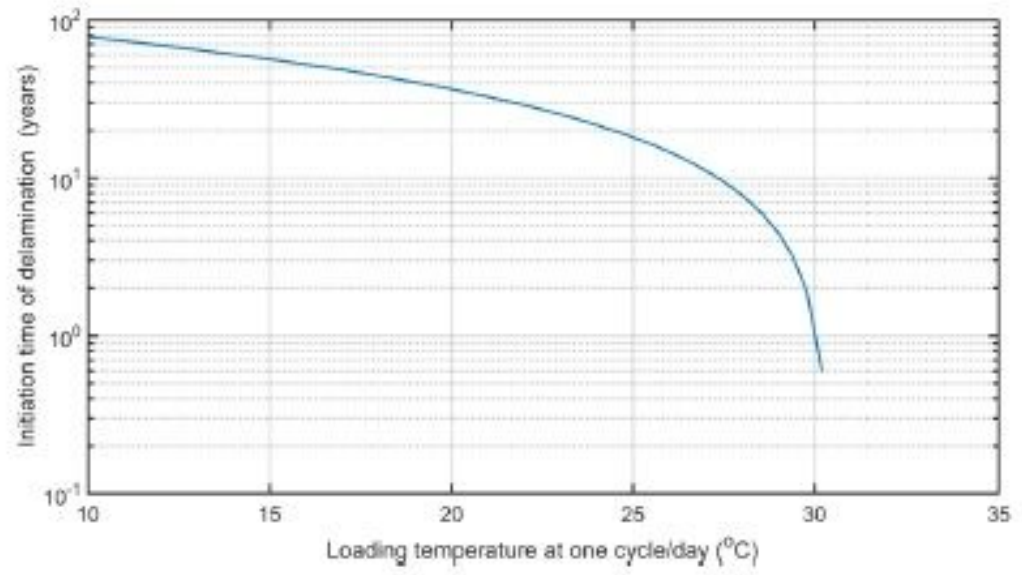

(b)

\section{Figure 8}

a) Initiation time of delamination versus loading relative humidity percent at one cycle/day, b) Initiation time of delamination versus loading temperature. 


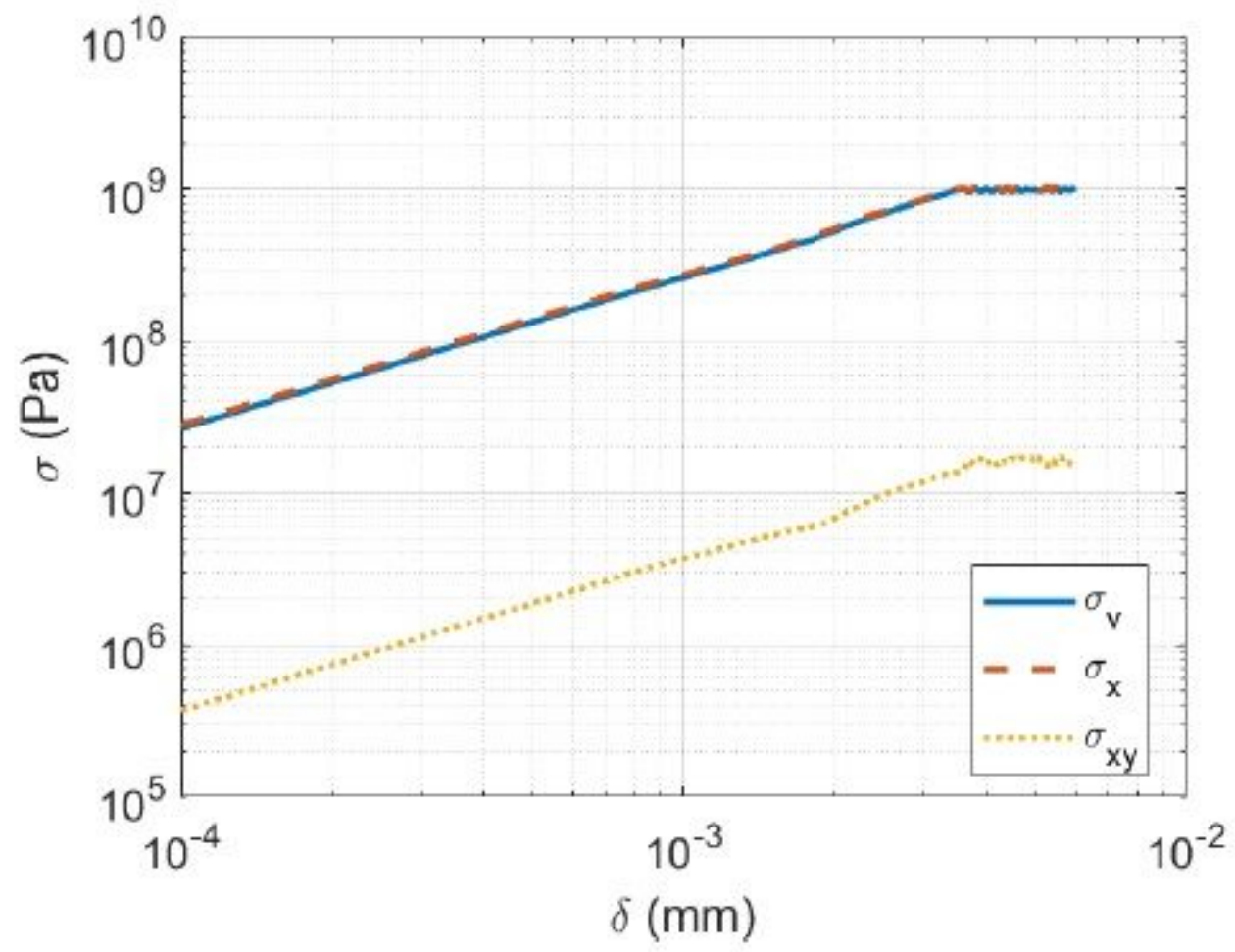

Figure 9

Comparison of various components of stress. 